\title{
Working
}

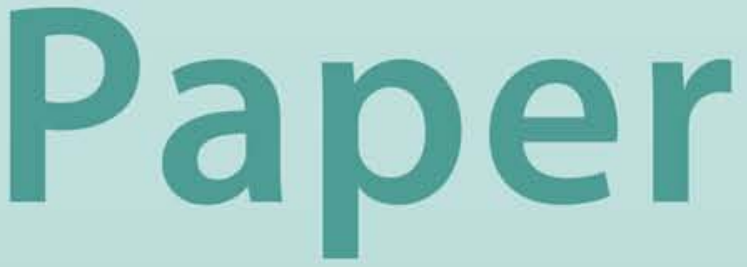




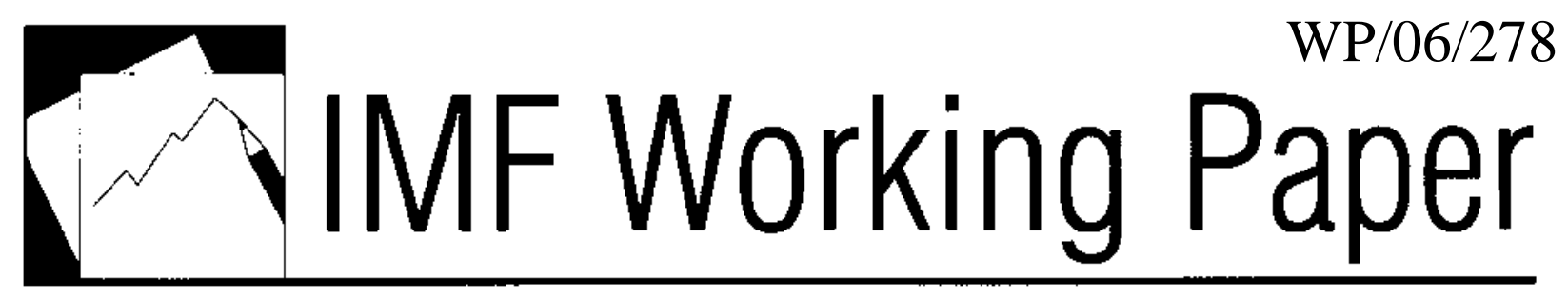

\section{Implementing Inflation Targeting: Institutional Arrangements, Target Design, and Communications}

Geoffrey Heenan, Marcel Peter, and Scott Roger 


\title{
IMF Working Paper
}

Monetary and Capital Markets Department

\section{Implementing Inflation Targeting: Institutional Arrangements, Target Design, and Communications}

\author{
Prepared by Geoffrey Heenan, Marcel Peter, and Scott Roger ${ }^{1}$
}

Authorized for distribution by Peter Stella

December 2006

\begin{abstract}
This Working Paper should not be reported as representing the views of the IMF. The views expressed in this Working Paper are those of the author(s) and do not necessarily represent those of the IMF or IMF policy. Working Papers describe research in progress by the author(s) and are published to elicit comments and to further debate.

Transparency is a central element in most aspects of the design and operation of inflation targeting regimes. This paper focuses on three elements of inflation targeting most closely associated with transparency: (i) the institutional arrangements supporting inflation targeting; (ii) the specification of the inflation target; and (iii) the central bank's policy communications. The paper is primarily aimed at providing practical advice to countries planning to develop an inflation targeting framework, but many of the issues are relevant for any credible, independent monetary policy.

JEL Classification Numbers:E42, E52, E58

Keywords: Monetary Policy, Inflation targeting

Author’s E-Mail Addresses: gheenan@imf.org; marcel.peter@snb.ch; sroger@imf.org

\footnotetext{
${ }^{1}$ Geoffrey Heenan and Scott Roger are IMF staff members; Marcel Peter is with the Swiss National Bank. This paper has benefited from comments and suggestions from many colleagues at the IMF, as well as those from the Bank of Canada, the Bank of England, the Reserve Bank of New Zealand, the Reserve Bank of Australia, and the Swiss National Bank. We are also grateful to Patricia Mendoza for assistance in preparing the document for publication. Any remaining errors and omissions are our own.
} 


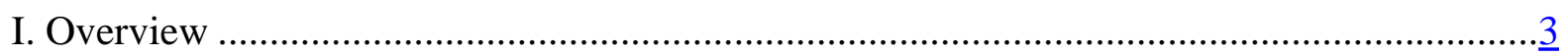

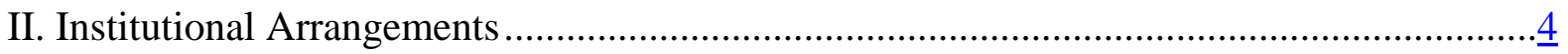

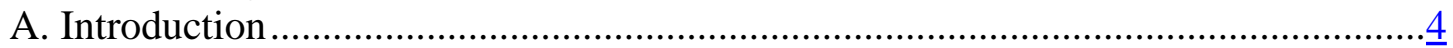



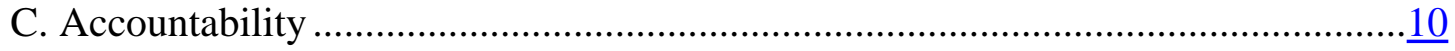

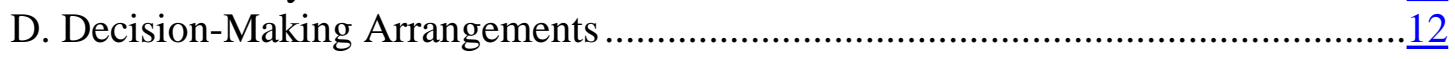

III. Inflation Target Design .................................................................................. 17

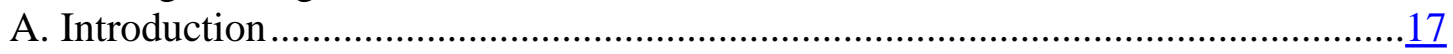

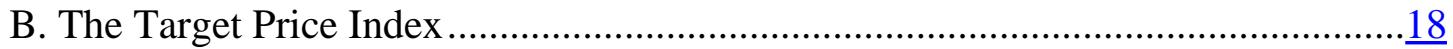

C. The Target Rate of Inflation.................................................................... $\frac{21}{24}$

D. The Target Horizon............................................................................



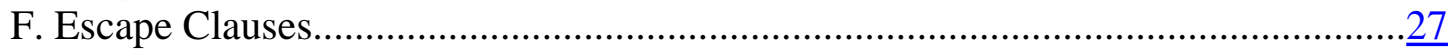

IV. Monetary Policy Communications .................................................................... 27

A. The Role of Policy Communication Activities ................................................27

B. Audiences, Objectives, and Modes of Central Bank Communication.................... $\frac{28}{33}$

C. Managing Central Bank Communications …...................................................

D. Reporting on Policy Decisions and Performance ...............................................

E. Other Communication Activities..................................................................... 43

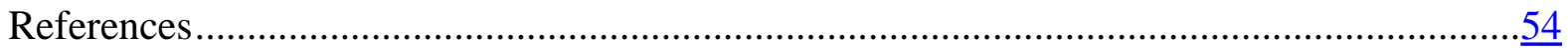

Tables

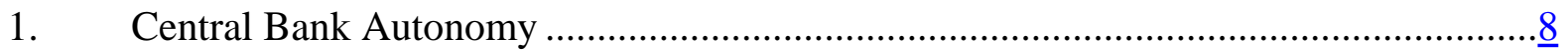

2. Central Bank Accountability and Policy Transparency ..........................................12

3. Central Bank Decision Making .......................................................................13

4. Inflation Target Design ...................................................................................

5. Communications Audiences, Objectives, and Modes of Communication ...................

6. Central Bank Website Coverage ........................................................................ 48

Figures

1. Chile: Inflation Targets and Outcomes, 1996-2006 ............................................20

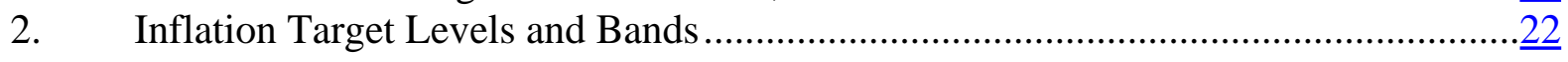

Appendix: The Inflation Report........................................................................... 49 


\section{OVERVIEW}

Inflation targeting (IT) regimes can be described as comprising the following basic elements: ${ }^{2}$

- An explicit central bank mandate to pursue price stability as the primary objective of monetary policy, together with accountability for performance in achieving the objective;

- Explicit quantitative targets for inflation;

- Policy actions based on a forward-looking assessment of inflation pressures, taking into account a wide array of information;

- Increased transparency of monetary policy strategy and implementation.

Of these elements, nearly all have an explicitly public dimension, underscoring the importance of transparency in nearly all aspects of their design and operation. Curiously, however, discussion of requirements for successful inflation targeting tends to overlook what is needed to achieve such transparency, focusing instead on the more technical issues of monetary policy formulation and implementation, including data needs, forecasting technology, market operations, and so on.

This paper focuses on the three elements of inflation targeting most closely associated with increased transparency. These are:

- The institutional arrangements establishing the necessary autonomy to pursue the inflation objective, together with effective accountability for the conduct of monetary policy, and a central bank decision-making framework that reinforces policy autonomy and accountability;

- The specification of an inflation target in a way that balances the need for a clear performance benchmark with the need for flexibility to take other macroeconomic and financial considerations into account in achieving the inflation objective; and

- A communications strategy designed to provide effective public accountability, underpin central bank credibility and autonomy, and anchor forward-looking inflation expectations.

The paper is aimed at assisting central banks, especially in emerging market and developing countries, seeking to develop the necessary "infrastructure" for inflation targeting. The paper draws as much as possible on the views, experience, and advice of practitioners of inflation targeting, including articles and papers written by central bankers, as well as on the expertise contained in technical assistance reports on inflation targeting prepared by the IMF's

\footnotetext{
${ }^{2}$ Adapted from Mishkin (2004a).
} 
Monetary and Capital Markets Department (MCM). ${ }^{3}$ In preparing the paper, the key objectives have been to identify the main practical issues that need to be addressed in the various areas and what the range of options appears to be and, if possible, to suggest which options can be recommended as "best practice.” The paper does not, however, provide advice on the operation and formulation of monetary policy.

Many of the issues covered in this paper are relevant for any credible, independent monetary policy, not just inflation targeting. It is often the case that inflation targeting is adopted in place of either an exchange rate regime or an "eclectic" regime with little credibility. In such circumstances it is important to clarify the central bank's objectives, responsibilities, and accountabilities in order to provide appropriate incentives and strengthen policy credibility. The same would apply if the central bank were adopting a money targeting strategy. It is not clear whether some of these features are significantly more important for a credible inflation targeting regime than for a credible money targeting regime. What is clear, however, is that the issues covered in this paper are more important for these regimes than for an eclectic regime with multiple targets, or for a regime in which there is little room for discretion.

The structure of the paper is as follows. In Section II, institutional arrangements in support of the inflation targeting framework are discussed. These include the necessary degree of central bank autonomy to pursue inflation targeting; the associated accountability and transparency requirements associated with the mandate; and the design of decision-making arrangements to support the autonomy, accountability, and credibility of the central bank. Section III reviews the main decisions and options faced in designing an inflation target explicitly intended to provide a public benchmark for assessing central bank policy performance. These include how the target is determined, what the target horizon should be, which price index to focus on, what the level of the target should be, and whether a target band should be specified. Section IV focuses on the main elements of central bank communications, including their role in an inflation targeting framework, the range of activities involved, and management issues.

\section{Institutional ArRangements}

\section{A. Introduction}

The credibility of inflation targeting is likely to be enhanced by a high degree of central bank autonomy in policy formulation, coupled with strong accountability arrangements for policy performance. It is also important for the central bank to be seen to have a decision-making framework that consistently gives priority to achievement of the inflation objective. In each of these areas, transparency plays a key role in signaling commitment and in ensuring discipline in the policymaking process. There are now several papers that provide excellent overviews of the complex range of issues involved in the design of the central bank's

\footnotetext{
${ }^{3}$ Technical assistance/cooperation on inflation targeting issues has been provided by MCM to Albania, Armenia, Colombia, Costa Rica, Czech Republic, Egypt, Guatemala, Indonesia, Poland, Romania, Slovakia, Thailand, Turkey, and Ukraine.
} 
institutional framework, as well as detailed descriptions of the spectrum of actual arrangements. These include IMF (1998), Lybek and Morris (2004), and Tuladhar (2005). ${ }^{4}$

This section focuses on three elements of the central bank's institutional arrangements that are particularly relevant in moving towards inflation targeting:

- The kind of autonomy the central bank needs to pursue inflation targeting;

- The design of accountability mechanisms; and

- Procedures and decision-making arrangements to support the focus on achieving the inflation target.

\section{B. Central Bank Autonomy}

Substantial central bank autonomy from political and fiscal policy pressures is regarded as essential to the credibility of inflation targeting. Providing a high degree of autonomy is widely viewed as helping to ensure that achievement of the inflation objective will not be subordinated to achievement of other policy objectives. Moreover, to anchor expectations and strengthen policy credibility, it is important for the public at large to perceive the central bank as being insulated from political pressures to pursue inflationary policy.

In establishing institutional arrangements to support inflation targeting, distinctions may usefully be drawn between goal, target, and instrument autonomy. ${ }^{5}$ Goal autonomy refers to the independent authority of the central bank to define the ultimate objectives of monetary policy; in particular, whether price stability should be the primary goal. Even if the central bank lacks this authority, it may have target autonomy, allowing it to specify the level and details of an inflation target that would be consistent with the broadly set goal of price stability. Finally, the central bank may have operational autonomy, giving it independent authority to use or set its monetary policy instruments to achieve its inflation target.

\section{Goal autonomy}

Goal autonomy is less important than goal prioritization. In all inflation targeting countries, the basic goals of monetary policy are established in central bank legislation rather than delegated to the central bank (Table 1). The more critical practical issues have been: (i) how to establish an enduring commitment to price stability as the primary goal of monetary policy, regardless of whether this goal is set by the government or central bank, and (ii) how to translate the commitment to a goal into an effective operational framework. Moreover,

\footnotetext{
${ }^{4}$ Several other studies seek to measure independence of central banks, and some also examine the extent to which central bank independence improves macroeconomic performance. For a comprehensive review of existing studies, see Arnone, Laurens, and Segalotto (2006).

${ }^{5}$ See, e.g., Debelle and Fischer (1994), IMF (1998).
} 
there is a strong case against giving the central bank goal autonomy, even in principle. ${ }^{6}$ In most countries the goal of price stability is embedded in central bank legislation. ${ }^{7}$ However, in many cases the wording of the legislation is somewhat ambiguous as to the priority to be given to this goal as opposed to other goals, including the exchange rate, balance of payments, growth, employment, and financial stability objectives. Adoption of inflation targeting requires, at minimum, clarification of the commitment to price stability or low inflation as the first priority of monetary policy.

Prioritization of the goal of price stability can be achieved in numerous ways. Increasingly, price stability has been established as the primary goal of monetary policy in central bank act revisions prior to the adoption of inflation targeting. However, in several countries, notably including EU accession countries, although price stability may be specified in the central bank act as the primary goal of monetary policy, the legislation delegates to the central bank the decision on which policy framework should be adopted to achieve that goal. Consequently, such legislation leaves it up to the central bank whether to achieve price stability through an exchange rate anchor, monetary targeting, or inflation targeting. In some other cases (e.g., Australia and Canada), rather than modifying the central bank act, the government and central banks have published bilateral agreements interpreting the existing omnibus central bank legislation to give first priority to the goal of domestic price stability. In some other cases, legislation to define price stability as the primary goal of monetary policy has followed rather than preceded implementation of inflation targeting. Whatever the precise method for setting price stability as the primary goal, a key common feature is that, although the government retains the power to set the policy goal, the government of the day cannot readily change the goal, and must do so publicly. This aspect helps to ensure that the adoption of inflation targeting is unlikely to be easily overturned.

In practice, adoption of inflation targeting generally requires a broad political consensus. Central banks have not adopted inflation targeting unilaterally without the consent of the government of the day for two reasons: (i) the government could react by limiting the independence of the central bank (by legislation or otherwise) if there were insufficient political backing for inflation targeting, and (ii) the successful implementation of inflation targeting requires the support or cooperation of the fiscal authorities. In particular, if fiscal policy is on an unsustainable path, or based on assumptions or objectives inconsistent with the inflation objectives, then the credibility or feasibility of inflation targeting may be compromised. This suggests that the credibility of the adoption of inflation targeting depends less on whether the central bank or government specifies the goal than on whether there is a clear and public commitment by both to take the actions necessary to achieve the goal of price stability.

\footnotetext{
${ }^{6}$ See, e.g., Fischer $(1995,2006)$ or Mishkin (2000). The key arguments are that giving the central bank full autonomy in setting the goal of monetary policy is inherently undemocratic and could lead to the imposition of preferences different from those that are socially optimal, with adverse welfare consequences.

${ }^{7}$ Tuladhar (2005), Table 1.
} 


\section{Target autonomy}

Specifics of inflation targets typically are set by the central bank, either jointly with the government or unilaterally (Table 1). Of the 24 current inflation targeters, 4 have targets specified by the government, 8 by the central bank, and 12 are set jointly by the government and central bank. In practice, close consultation is usually involved whichever institution has the formal authority. It is in the interest of both the government and the central bank to achieve the maximum common "ownership" of the target specification, and for this to be understood by the public. An important consideration in involving the government in deciding on the target is to ensure that the fiscal authorities take the inflation target seriously in their planning and decisions. ${ }^{8}$ For this reason, even if the central bank has the unilateral authority to specify the inflation target, it is still sensible to pursue a consultative approach in setting target parameters and to have the government support the target specification publicly.

In several inflation targeting countries, the government reserves the right to suspend or override the inflation target on a temporary basis (Table 1$).{ }^{9}$ In such cases, it is common practice to indicate the kinds of circumstance in which the override might occur (e.g., a major natural disaster, war, or extreme turbulence in the foreign exchange market), establish a transparent process for directing the central bank to suspend its inflation target, and to specify that such directives are valid only for a short period (e.g., three months).

Regular reviews of inflation target specifications should be considered. In most inflationtargeting countries, there is no formal procedure for reviewing the specification of the inflation target. This is problematic, either because adjustments in target parameters may be misinterpreted as opportunistic, undermining policy credibility, or because adjustments may be avoided for fear of misinterpretation. In a few countries, however, there is an established routine for reviewing the inflation target specification. In New Zealand, the inflation target is notionally specified for a five year period, but either side can seek renegotiation at any time. In practice, reviews have tended to follow changes in Government. In Canada's case, the inflation target agreement between the Bank of Canada and the Minister of Finance is subject to review on a five-yearly basis. The regular nature of such reviews helps to divorce any adjustments from current political issues, and also provides adequate lead time for any research needed to support modifications to the target parameters or other elements of the IT framework.

\footnotetext{
${ }^{8}$ Areas where it may be particularly important to ensure consistency include: whether wage policies are in line with the inflation targets; whether the government's revenue and expenditure forecasts are consistent with the targets; and whether planned changes in administered prices may make it very difficult to achieve the inflation objectives. In the latter case, the targets may need to be designed taking into account planned changes in administered prices.

${ }^{9}$ Briault et al. (1996); Briault et al. (1997); De Haan, Amtenbrink, and Eijffinger (1998).
} 
Table 1. Central Bank Autonomy

\begin{tabular}{|c|c|c|c|c|c|}
\hline Country & $\begin{array}{c}\text { Goal } \\
\text { Autonomy }\end{array}$ & Target Autonomy & & Instrument Auto & my \\
\hline & $\begin{array}{l}\text { Legislated } \\
\text { Goal }\end{array}$ & $\begin{array}{c}\text { Target } \\
\text { Specification 1/ }\end{array}$ & $\begin{array}{l}\text { Government } \\
\text { Override 2/ }\end{array}$ & $\begin{array}{c}\text { Credit to } \\
\text { Government 3/ }\end{array}$ & $\begin{array}{l}\text { Gov't Participation } \\
\text { in Policymaking 4/ }\end{array}$ \\
\hline Australia & Multiple goals & $\mathrm{G}+\mathrm{CB}$ & Yes & Yes & Voting member \\
\hline Brazil & Inflation target & G & No & No & No \\
\hline Canada & Multiple goals & $\mathrm{G}+\mathrm{CB}$ & Yes & Yes, limited & Non-voting \\
\hline Chile & $\begin{array}{l}\text { Price + financial } \\
\text { stability }\end{array}$ & $\mathrm{CB}$ & Yes & Yes & Non-voting $^{5}$ \\
\hline Colombia & Price stability & $\mathrm{CB}$ & Yes & No & Voting member \\
\hline $\begin{array}{l}\text { Czech } \\
\text { Republic }\end{array}$ & Price stability & $\mathrm{G}+\mathrm{CB}$ & No & No & Non-voting \\
\hline Hungary & Price stability & $\mathrm{G}+\mathrm{CB}$ & No & No & Non-voting \\
\hline Iceland & Price stability & $\mathrm{G}+\mathrm{CB}$ & No & No & No \\
\hline Indonesia & $\begin{array}{l}\text { Currency } \\
\text { stability }\end{array}$ & $\mathrm{G}+\mathrm{CB}$ & No & No & No \\
\hline Israel & Price stability & G & No & No & No \\
\hline Korea & Price stability & $\mathrm{G}+\mathrm{CB}$ & No & Yes & Non-voting \\
\hline Mexico & Price stability & $\mathrm{CB}$ & No & Yes & Non-voting \\
\hline New Zealand & Price stability & $\mathrm{G}+\mathrm{CB}$ & Yes & Yes & No \\
\hline Norway & $\begin{array}{l}\text { Low, stable } \\
\text { inflation }\end{array}$ & G & Yes & No & No \\
\hline Peru & $\begin{array}{l}\text { Monetary } \\
\text { stability }\end{array}$ & $\mathrm{CB}$ & No & No & Voting member \\
\hline Philippines & Price stability & $\mathrm{G}+\mathrm{CB}$ & No & Yes, limited & Voting member \\
\hline Poland & Price stability & $\mathrm{CB}$ & No & No & Non-voting \\
\hline Romania & Price stability & $\mathrm{G}+\mathrm{CB}$ & No & No & No \\
\hline Slovakia & Price stability & CB & No & No & No \\
\hline South Africa & $\begin{array}{l}\text { Currency } \\
\text { stability }\end{array}$ & $\mathrm{G}+\mathrm{CB}$ & Yes & Yes & No \\
\hline Sweden & Price stability & CB & No & No & Non-voting \\
\hline Thailand & $\begin{array}{l}\text { Monetary } \\
\text { stability }\end{array}$ & $\mathrm{CB}$ & No & Yes & No \\
\hline Turkey & Price Stability & $\mathrm{G}+\mathrm{CB}$ & No & No & Non-voting \\
\hline $\begin{array}{l}\text { United } \\
\text { Kingdom }\end{array}$ & Price stability & G & Yes & No & Non-voting \\
\hline $\begin{array}{l}\text { Notes and Sou } \\
\text { 1/ G = Govern } \\
\text { 2/ Roger and S } \\
\text { 3/ Tuladhar (2C } \\
\text { 4/ Tuladhar (2C } \\
\text { 5/ Finance Min }\end{array}$ & $\begin{array}{l}\text { es: } \\
\text { ent; CB = Centra } \\
\text { ne (2005), Tabl } \\
\text { 5), Table } 6 . \\
\text { 5), Table } 3 \text {. }\end{array}$ & nk. & 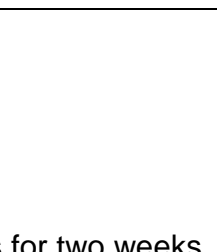 & & \\
\hline
\end{tabular}

\section{Instrument autonomy}

A high degree of central bank autonomy in the setting of its policy instruments is essential for credible and effective inflation targeting. Once the central bank has been given the mandate and responsibility to pursue an inflation objective, it needs also to be given the 
power to set its policy instruments to achieve that objective. This has three important implications:

- The operation of monetary policy should not be compromised by fiscal dominance;

- Decisions of the central bank on policy instrument settings should not be subject to government approval or veto;

- Policy decision-making should be clearly free from direct or indirect government pressure or coercion.

In practice, limits on the instrument autonomy of inflation targeting central banks do not appear to be binding. As indicated in Table 1, in many cases, there is some scope for central bank financing of government, or the government retains powers to override the central bank's instrument setting decisions, or government officials may participate directly in decision-making. This underscores the fact that de jure autonomy may matter less than de facto autonomy. As long as there is a strong government commitment to the inflationtargeting framework, the government is unlikely to use its powers to interfere in monetary policy decisions.

Legal and institutional arrangements should be reviewed to strengthen the central bank's instrument autonomy. Whatever the prior degree of central bank instrument autonomy on a de facto basis, establishing a credible commitment to inflation targeting depends heavily on public perceptions (including those of international financial market participants). For this reason, very explicit steps may be needed to bolster credibility. Five areas in particular areas may be highlighted:

- There should be strict limits, or a total prohibition, on central bank financing of the government (including all public sector entities), especially for those countries seeking to overcome a history of fiscal dominance. ${ }^{10}$

- Legislation or, at minimum, a clear statement from the government, should transfer full authority for day-to-day decisions on monetary policy settings to the central bank, particularly in countries where the finance ministry has traditionally had a final say over interest rate changes or exchange rate policy. If the government retains a say over the exchange rate, this should be limited to exceptional circumstances and the specifics of when and how those powers would be exercised should be made public. ${ }^{11}$

- The central bank's key decision-making bodies should be insulated from potential conflicts of interest faced by external members of the key policy decision-making

\footnotetext{
${ }^{10}$ See IMF (1998) and Cottarelli (1995) on means of limiting central bank credit to the government.

${ }^{11}$ See IMF (1998) and Cottarelli (1994).
} 
bodies. In particular, the participation of government officials should be limited. ${ }^{12}$ Potential conflicts of interest, and unfair access to privileged information, should also rule out participation of commercial bankers or business executives in the central bank's monetary policy decision-making body, and various other restrictions on committee members' outside activities may be required..$^{13}$

- Members of the central bank's decision-making bodies should be protected from potential external pressures. Procedures and rules for appointment and dismissal of senior central bank staff and board members should be reviewed and clarified as necessary to promote public confidence in the autonomy of the central bank's decision making. This should include nomination procedures, qualification requirements, duration of appointments, remuneration and financial disclosure arrangements, legal immunities, and grounds and procedures for dismissal. ${ }^{14}$ Lybek and Morris (2004) and Tuladhar (2005) document practices in a wide range of countries and provide some recommendations as to how to protect policymakers from external pressures. Their discussions of international practices indicate clearly, however, that a variety of approaches can be taken to achieve the desired objective of bolstering decision-makers' independence.

- The central bank's capital position, operational financing arrangements, and accounting and auditing practices should also be reviewed. Stella (2005) notes that a weak central bank financial position might be inconsistent with achieving or maintaining price stability. ${ }^{15}$ This could both undermine the credibility of monetary policy and interfere with policy implementation. Consequently, strengthening the capitalization of the central bank might be appropriate, together with measures to ensure the central bank's profitability on an ongoing basis. In addition, Stella argues that significant improvements in accounting and auditing practices can help greatly to improve the central bank's financial transparency. ${ }^{16}$ To insulate the central bank from political interference through its budget, budgetary or profit-sharing arrangements made with the government should be made public and, preferably, placed on a multiyear basis.

\section{Accountability}

Central bank accountability for performance in relation to the inflation target is a natural corollary of central bank autonomy in policy implementation and can help to reinforce such autonomy. In a democratic environment, an autonomous central bank requires some form of

\footnotetext{
${ }^{12}$ Tuladhar (2005), documents restrictions on government participation in both voting and nonvoting capacities (Table 3).

${ }^{13}$ Lybek and Morris (2004) discuss various measures to limit conflicts of interest.

${ }^{14}$ Tuladhar (2005), Table 4, documents appointment and dismissal provisions for central bank governors in most inflation targeting countries, and Table 5 documents terms of appointments for central bank boards.

${ }^{15}$ See also Ize (2005).

${ }^{16}$ See also Sullivan $(2003,2005)$.
} 
accountability to provide it with legitimacy and credibility. Further, accountability provides incentives to the central bank to seek to meet its targets and to communicate its decisions and actions transparently.

Mechanisms for providing central bank policy accountability vary across countries, with some having quite formal arrangements and others less so (Table 2). ${ }^{17}$ The main mechanisms used to hold the central bank accountable for its policy performance and actions include:

- Publication of regular inflation or monetary policy reports;

- Publication of special reports or open letters in the event of significant misses of the target;

- Use of "escape” clauses to limit central bank accountability in particular circumstances, as well as to indicate, in advance, how policy will react to certain kinds of shocks;

- Publishing minutes of policy meetings within a reasonable time frame;

- Monitoring by the executive or legislature (in the form of a special report to executive/parliament or a hearing);

- Monitoring by a central bank supervisory board;

- Dismissal of the decision maker(s) (governor, board members) in case of unsatisfactory performance.

Transparency is a crucial means of enhancing central bank accountability to the public at large. In many countries, the central bank's reporting to the public on its policy decisions and actions goes far beyond what is formally required under the law or an inflation targeting agreement. Such efforts play an important educational role, but are also geared toward establishing the central bank's accountability to the public at large, rather than strictly to the central bank’s supervisory board, the legislature, or the government of the day.

${ }^{17}$ See Roger and Stone (2005), Tuladhar (2005), and Lybek and Morris (2004) 
Table 2. Central Bank Accountability and Policy Transparency

\begin{tabular}{|c|c|c|c|c|c|}
\hline Country & $\begin{array}{l}\text { Publication of } \\
\text { Policy Minutes }\end{array}$ & $\begin{array}{l}\text { Testimony / } \\
\text { Reporting to } \\
\text { Parliament }\end{array}$ & $\begin{array}{c}\text { Monetary } \\
\text { Policy Report }\end{array}$ & $\begin{array}{c}\text { Specific Reporting } \\
\text { on Large Target } \\
\text { Misses } 1 /\end{array}$ & $\begin{array}{c}\text { Use of Escape } \\
\text { Clauses 2/ }\end{array}$ \\
\hline Australia & No & Yes & Quarterly & No & No \\
\hline Brazil & Yes, 8-day lag & Yes & Quarterly & Yes & No \\
\hline Canada & No & Yes & $\begin{array}{l}\text { Semi-annual + } \\
\text { update }\end{array}$ & Yes & No \\
\hline Chile & Yes, 90-day lag & Yes & Quarterly & No & No \\
\hline Colombia & No & Yes & Quarterly & No & No \\
\hline $\begin{array}{l}\text { Czech } \\
\text { Republic }\end{array}$ & Yes & Yes & Quarterly & No & Explicit description \\
\hline Hungary & Yes & Yes & $\begin{array}{l}\text { Semi-annual + } \\
\text { update }\end{array}$ & No & No \\
\hline Iceland & No & No & Quarterly & Yes & No \\
\hline Indonesia & No & Yes & Quarterly & Yes & No \\
\hline Israel & Yes & Yes & Semi-annual & No & No \\
\hline Korea & No & Yes & Semi-annual & No & No \\
\hline Mexico & No & Yes & Quarterly & No & No \\
\hline New Zealand & No & Yes & Quarterly & Yes & Explicit description \\
\hline Norway & No & Yes & 3 per year & No & No \\
\hline Peru & No & No & 3 per year & No & No \\
\hline Philippines & Yes & Yes & Quarterly & Yes & Explicit description \\
\hline Poland & No & Yes & Quarterly & No & Explicit description \\
\hline Romania & No & No & Quarterly & No & Explicit description \\
\hline Slovakia & No & No & Quarterly & No & Explicit description \\
\hline South Africa & No & No & Semi-annual & No & Explicit description \\
\hline Sweden & Yes & Yes & 3 per year & Yes & Explicit description \\
\hline Thailand & No & No & Quarterly & Yes & No \\
\hline Turkey & Yes & No & Quarterly & Yes & No \\
\hline $\begin{array}{l}\text { United } \\
\text { Kingdom }\end{array}$ & Yes & Yes & Quarterly & Yes & No \\
\hline
\end{tabular}

Notes and Sources:

$1 /$ Roger and Stone (2005), Table 3.

2/ Tuladhar (2005), Table 2.

\section{Decision-Making Arrangements}

The decision-making structure in an inflation targeting central bank should aim to achieve several objectives. These include ensuring the central bank's decision-making autonomy; bringing appropriate knowledge and expertise to bear on policy decisions; promoting efficient and effective policy decisions; and ensuring meaningful accountability for policy decisions. Trade-offs are likely to be faced in achieving these objectives, and these will vary from one country and culture to another. Consequently, there is unlikely to be a "best" 
Table 3. Central Bank Decision Making

\begin{tabular}{|c|c|c|c|}
\hline Country & Decision-Making Body $1 /$ & $\begin{array}{l}\text { Internal/External } \\
\text { Membership }\end{array}$ & $\begin{array}{l}\text { Number of Policy Rate } \\
\text { Meetings Per Year } 2 /\end{array}$ \\
\hline Australia & Bank Board & $3 / 6$ & 12 \\
\hline Brazil & MPC (COPOM) & $9 / 0$ & 8 \\
\hline Canada & Governing Council & $6 / 0$ & 8 \\
\hline Chile & Executive Board & $5 / 0$ & 12 \\
\hline Colombia & Board of Directors & $6 / 1$ & 12 \\
\hline Czech Republic & Bank Board & $7 / 0$ & 12 \\
\hline Hungary & Monetary Council & $4-6 / 1-3$ & 12 \\
\hline Iceland & Board of Governors & $3 / 0$ & 6 \\
\hline Indonesia & Board of Governors & $6-9 / 0$ & 12 \\
\hline Israel & Governor 3/ & Advisory council & 12 \\
\hline Korea & MPC & $2 / 5$ & 12 \\
\hline Mexico & Board of Governors & $5 / 0$ & 12 \\
\hline New Zealand & Governor 4/ & $8 / 2$ & 8 \\
\hline Norway & Executive Board & $2 / 5$ & 8 \\
\hline Peru & Board of Directors & $1 / 6$ & 12 \\
\hline Philippines & Monetary Board & $1 / 6$ & 8 \\
\hline Poland & Monetary Policy Council & $1 / 9$ & 12 \\
\hline Romania & Board of Directors & $4 / 5$ & 12 \\
\hline Slovakia & Bank Board & $8-11 /<3$ & 12 \\
\hline South Africa & MPC & $8 / 0$ & 6 \\
\hline Sweden & Executive Board & $6 / 0$ & 8 \\
\hline Thailand & MPC & $3 / 4$ & 8 \\
\hline Turkey & MPC & $5 / 0$ & 12 \\
\hline United Kingdom & MPC (since 1997) & $5 / 4$ & 12 \\
\hline
\end{tabular}

Notes and Sources:

1/ Roger and Stone (2005) and central bank websites.

$2 /$ In virtually all countries, meetings can be held more frequently if necessary.

$3 /$ On advice of MPC.

4/ Advised by Overnight Cash Rate Advisory Group.

model. And, in practice, the decision-making structures of inflation targeting central banks vary considerably. ${ }^{18}$

Two main sets of issues should be taken into consideration in designing the decision-making structure. The first set of issues concerns the degree to which decisions on monetary policy formulation and implementation should be separated from supervision of the bank for the

${ }^{18}$ See Lybek and Morris (2004), Tuladhar (2005), and Vandenbussche (2006). 
purposes of policy accountability. The second set of issues concerns the design of the committee making policy decisions. This includes, in particular, the composition of the committee and the decision-making process.

\section{Policy supervision versus policy implementation}

One of the main issues in the design of the central bank's management structure is how to minimize potential conflicts among different functions of management. As in private sector enterprises, a particularly important area of potential conflict is between the executive responsibilities of the central bank, in terms of policy formulation and implementation, and the supervision of the executive function in the interests of the shareholder-in this case the government and general public. Conflict can arise because impartial monitoring and assessment of whether the central bank is pursuing the tasks assigned to it is difficult if the assessors are also responsible for the key decisions on policy formulation and implementation. Moreover, the skills and attributes needed for effective supervision of management are likely to differ from those appropriate for the effective execution of policy.

The most transparent approach to dealing with this issue is to establish a formal, two-tier management structure involving a supervisory board charged with responsibility for monitoring and evaluating the central bank's performance in relation to its assigned objectives, and a separate monetary policy committee (MPC) responsible for the formulation and implementation of monetary policy. ${ }^{19}$

In many countries, however, a less formal division of responsibilities takes place. As indicated in Table 3 (see also Tuladhar, 2005, Tables 8 and 9) many central bank boards are formally executive in character. In such cases, a common practice is for the board to substantially delegate policy formulation and implementation decisions to a largely internal central bank MPC, whose recommendations it would routinely approve. ${ }^{20}$ The exact manner in which this delegation occurs varies, as does the extent to which the recommendations of the MPC to the board are regarded as decisions or advice. ${ }^{21}$ This approach resembles a twotier board structure, largely separating the supervisory and executive functions of management, and allows for important differentiation of skills and knowledge. This approach would be particularly appropriate if the board is substantially made up of outside members.

\footnotetext{
${ }^{19}$ IMF (1998). In such an arrangement, it is recommended that the supervisory board be chaired and predominantly composed of outsiders (to ensure their independence of the central bank, as well as to ensure a reasonable balance of occupational or regional representation to provide political legitimacy to the group), while the body responsible for policy implementation should be largely composed of central bank staff (to ensure that appropriate expertise is brought to the decision-making table and to ensure that decisions are independent of external influences).

${ }^{20}$ The internal MPC might still include some board members and other outsiders, such as finance ministry representatives, but decisions would still be determined by a majority of insiders.

${ }^{21}$ Lybek and Morris (2004) and Tuladhar (2005) describe in some detail the diversity of arrangements seen in practice.
} 
A board acting on the advice of an internal MPC is less transparent than a more formal separation of supervisory and operational responsibilities. A basic concern is that the degree to which the board actually delegates policy decisions to the MPC may vary over time, at the discretion of the board. ${ }^{22}$ To minimize this problem, the board could consider establishing a protocol clarifying that it would take the recommendations of the MPC except in exceptional circumstances, which the board would be required to explain in a public statement. In other words, the board would retain power to override the MPC, but would need to be transparent in exercising that power.

Another approach involves a single decision-making body, but with the roles of members somewhat differentiated. In countries where policy decisions are not effectively delegated to an MPC, external members of the board may focus primarily on supervision of the decisionmaking process, while internal members of the board focus more on the substance of policy formulation and implementation.

In countries where the board's role is primarily executive in character, mechanisms for external supervision are important. Examples of such mechanisms include not only the requirement to publish a regular monetary policy report, but also publication of minutes and regular appearance of board members before parliamentary committees.

\section{Design of monetary policy committees responsible for policy formulation and implementation}

The principal issues to consider in the design of the MPC are its membership and the decision-making rules. These issues, and the options and trade-offs to consider are discussed in depth in IMF (1998), Lybek and Morris (2004), Tuladhar (2005), and Vandenbussche (2006). Countries moving in the direction of increased central bank autonomy and accountability associated with inflation targeting should review the appropriateness of existing policy decision-making arrangements with the change in regime and make the arrangements public.

\section{Committee membership}

The main considerations in designing the MPC — as distinct from the board to which it is accountable-are to ensure that: (i) its members are well-qualified to make monetary policy decisions; (ii) its members are able to make policy decisions free of outside pressures or conflicts of interest; and (iii) the committee embraces a diversity of views but is a manageable size. As discussed in IMF (1998), Lybek and Morris (2004), Tuladhar (2005), these considerations generally lead to recommendations that:

- Government officials be either excluded from the MPC altogether or, at least, limited to a nonvoting role;

\footnotetext{
${ }^{22}$ Individual personalities are very important in this context. A forceful central bank governor may be highly effective in ensuring that MPC recommendations are accepted by the board. However, a forceful board chairman may be less willing to acquiesce to MPC recommendations.
} 
- Restrictions be placed on other non-central-bank members to exclude persons with conflicts of interest, either owing to their profession or to their financial interests; ${ }^{23}$

- Members should have a high standing in a professional field relevant to monetary policy decision making; ${ }^{24}$

- Membership terms of externally appointed members should be at least as long as the bodies that appointed them;

- Members of the central bank should form a majority on the MPC;

- All members should satisfy high standards of financial disclosure;

- The size of the committee should be kept fairly small in order to facilitate discussion of issues in some depth and reaching decisions within a reasonable timeframe. As shown in Table 3, the policy decision-making group in most inflation targeting central banks is between 5 and 10 persons.

\section{Decision-making rules ${ }^{25}$}

The key issue is whether to base decisions on a consensus-seeking approach or a more individualistic vote-based approach. In a few countries (Canada, Israel, New Zealand) policy decisions are made, in principle, by the governor alone. In practice, however, even in these countries governors decide on the advice of committees, so that decision making may be very similar to that in countries with more explicitly committee-based decisions. Vandenbussche (2006) argues that, although there is evidence that decisions by committees are better than autocratic decisions, and that discussion improves decisions, there is not a clearcut case for either the consensus or the majority voting approach. The consensus approach may promote discussion and information sharing, but it risks free-riding and undermining diversity of views. Majority voting, however, may weaken accountability and may also reduce the informational efficiency of decision making. In countries where good economic information is limited and there is heavy reliance on information, often anecdotal, from disparate sources, a more consensus-oriented approach may therefore be preferred to a less collegial majorityvoting approach.

The frequency of policy decision making also needs to be considered. In inflation targeting countries, policy decision-making meetings typically involve a comprehensive review of recent economic indicators and an assessment of their implications for future inflation. In practice, inflation targeting central banks have found it to be sufficient to meet no more than

\footnotetext{
${ }^{23}$ See Tuladhar (2005) Table 5 for an indication of restrictions on professional affiliations of MPC members in inflation targeting countries. See Lybek and Morris (2004) for a discussion of other restrictions.

${ }^{24}$ Svensson (2001) Lybek and Morris (2004). According to Fischer (1994) members should be "persons of recognized standing and professional experience in monetary, financial, and economic matters."

${ }^{25}$ See Fry and others (2000); Lybek and Morris (2004), Tuladhar (2005), Vandenbussche (2006).
} 
once per month to review the stance of policy (Table 3), and many meet only every six weeks or less frequently. With macroeconomic forecasting exercises typically conducted quarterly or, more rarely, every four months, the issue really boils down to whether the MPC should meet either once or twice between each of the major forecast-based policy reviews. This, in turn is likely to depend on how much relevant new data accumulates over the inter-forecast interval, and also how prone the economy is to shocks that call for adjustments in the policy stance.

\section{INFLATION TARGET DESIGN}

\section{A. Introduction}

A well-designed inflation target should:

- Anchor inflationary expectations - it should be relevant to a broad range of economic agents, signal a medium-term commitment by the central bank to low inflation, and be easy to understand by the general public.

- Provide a benchmark for central bank accountability - it should not be easily manipulated by the central bank, should be based on an index that is available on a timely and frequent basis, and should not be subject to significant revision.

- Be consistent with the central bank's objectives - its design should reflect the central bank's goal to maintain price stability while avoiding excessive short-run output volatility.

The parameters that should be specified in designing the inflation target include the price index to be used to measure inflation, the level of the inflation target, whether a point target or band should be used, and whether any escape clauses should be included in the specification.

There is a trade-off between choosing a simple inflation target design that is transparent and easy to understand, and a more complex design that is more technically consistent with the central bank's internal models of the inflation process. In general, central banks have emphasized the need for transparency in the designs of their inflation targets, and therefore have adopted uncomplicated frameworks. Further, central banks have tended to simplify their target design over time, for example by moving from core inflation measures to the headline Consumer Price Index (CPI) as the target.

One key point to be stressed is that the formal design of the inflation target is only part of the story of how central banks signal their commitment to their inflation objectives. The strength of this commitment is affected by the accompanying rhetoric and other forms of communication employed by each central bank. Thus, a weaker formal framework may be enhanced by unambiguous public announcements by the management of a central bank committing it to low inflation, whereas a strong formal framework may be undermined by unclear and contradictory policy statements by the central bank. 


\section{B. The Target Price Index}

In all inflation targeting countries, the target measure of inflation is based on the CPI. The CPI generally has the widest relevance for the general public, in that it is the most widely publicized price measure and most commonly used for indexation purposes. It is available with a short lag and (because of its use in indexation) usually not subject to revision. ${ }^{26}$

The choice between targeting the headline CPI and or a core measure depends mostly on how the CPI is calculated. Central banks have used core measures to exclude the effects of changes of particular components of the CPI when: (i) these prices may be irrelevant or have misleading information for the price stability objective; or (ii) price changes reflect exogenous shocks that are beyond the control of the central bank, including tax changes. In such cases the core CPI may be a better indicator of inflationary conditions than the headline figure.

In almost all inflation targeting countries, the target is specified in terms of the headline CPI rather than a measure of core inflation (Table 4). Although inflation targeting countries routinely calculate, report and use measures of core inflation in policy formulation and communications, the headline rate is generally used as the official target because it is more familiar to the public and is calculated by the statistics agency. In a few cases, including Australia, New Zealand, South Africa and the United Kingdom, inflation targets were originally specified in terms of the CPI excluding mortgage interest charges, but shifted to the headline CPI when their statistical agencies revised their methodologies to exclude these from the compilation of the CPI. In the Czech Republic, the target was initially defined as "net inflation," which excluded the effect of increases in administrative prices, so that the effects of deregulation during the transition to a market economy would not distort the measurement of underlying price pressures. In 2003, after the transition was completed, the Czech National Bank adopted to the headline CPI as its target variable.

\footnotetext{
${ }^{26}$ Alternative candidate measures include GDP deflators or wholesale or producer price indexes. The GDP deflator has the widest coverage, but suffers from several shortcomings. In open economies, especially those where exports differ markedly in nature from domestic demand, terms of trade movements will cause the GDP deflator to diverge from the rate of price increase observed by households. For this reason, it usually lacks public acceptance as a general price measure. In addition, it is generally subject to substantial revisions and is released with a longer lag than CPI or Producer Price Index (PPI). More restricted national accounts deflators, such as the domestic demand and personal consumption deflators, suffer less from the first issue, but share the second shortcoming. The PPI is available on a timely basis, but has restricted coverage. In particular, it excludes services, which are a substantial and growing proportion of consumption in most countries.
} 
Table 4. Inflation Target Design

\begin{tabular}{|c|c|c|c|c|}
\hline Country & $\begin{array}{l}\text { Inflation } \\
\text { Measure }\end{array}$ & $\begin{array}{c}\text { Calculation } \\
\text { Basis }\end{array}$ & $\begin{array}{c}\text { Commitment } \\
\text { Horizon }\end{array}$ & $\begin{array}{c}\text { Forecast } \\
\text { Horizon }\end{array}$ \\
\hline Australia & Headline CPI & y-on-y 2 l & medium-term & 4-6 qtrs. \\
\hline Brazil & Headline CPI & $y-o n-y$ & 1 year & $6-8$ qtrs. \\
\hline Canada & Headline CPI & $y-o n-y$ & 5 years & $6-8$ qtrs. \\
\hline Chile & Both headline and core CPI $1 /$ & y-on-y 2 I & medium-term & 8 qtrs. \\
\hline Colombia & Headline CPI & y-on-y 2 I & long-term & 8 qtrs. \\
\hline Czech Rep. & Headline CPI & y-on-y & Eurozone accession & $2-3$ years \\
\hline Hungary & Headline CPI & y-on-y 21 & medium-term & 10 qtrs. \\
\hline Iceland & Headline CPI & y-on-y & medium-term & $8-10$ qtrs. \\
\hline Indonesia & Headline CPI & y-on-y 21 & medium-term & 1 year \\
\hline Israel & Headline CPI & y-on-y & not specified & 2 years \\
\hline Korea & Headline CPI & y-on-y 2 l & 3 years & not specified \\
\hline Mexico & Headline CPI & y-on-y 2 l & not specified & $3 /$ \\
\hline New Zealand & Headline CPI & y-on-y 21 & medium-term & not specified \\
\hline Norway & Core CPI & y-on-y 2 l & not specified & 14 qtrs. \\
\hline Peru & Headline CPI & $y-o n-y$ & not specified & not specified \\
\hline Phillipines & Headline CPI & y-on-y $2 /$ & not specified & 2 years \\
\hline Poland & Headline CPI & $y-o n-y$ & medium-term & not specified \\
\hline Romania & Headline CPI & y-on-y (each qtr) & 2 years & not specified \\
\hline Slovakia & Headline CPI & ann. avg. (Dec.) & 3 years & 3 years \\
\hline South Africa & $\mathrm{CPI}$ excluding mortgage interest & $y-o n-y$ & not specified & 8 qtrs. \\
\hline Sweden & Headline CPI & y-on-y and ann. avg. & not specified & $1-2$ years \\
\hline Thailand & Core CPI & qtrly. avg. & not specified & 8 qtrs. \\
\hline Turkey & Headline CPI & $y$-on-y & 3 years & 8 qtrs. \\
\hline United Kingdom & Headline CPI & $y$-on-y & 1 year & 12 qtrs. \\
\hline
\end{tabular}

Sources: Various documents of national central banks.

1/ The Central Bank of Chile focuses on the core CPI for the next twelve months, and the headline CPI for longer horizons.

2/ Calculation method not explicitly defined, but based on common usage.

3/ The Bank of Mexico publishes qualitative forecasts for the end of the current year. 
In almost all cases, the target is currently defined in terms of the 12-month point-to-point rates of change in the target price index. Potential alternatives include annualized monthly (or quarterly) changes, or the change in the annual average price level. The choice between these methods involves a trade-off between reducing excessive short-term volatility of the measured inflation rate versus the timeliness of the measure with respect to current price developments. The annualized monthly or quarterly measure represents the most up-to-date information on price movements, but because of this may be very volatile and may not reflect underlying inflationary trends very well. In particular, it may be dominated by seasonal factors unless the price index is seasonally adjusted. The other methods reduce the volatility of measured inflation by averaging price movements over time. In the case of the point-topoint annual change, this is done over the previous year, while for the annual average change, the averaging extends back two years. Time averaging, however, has two important effects which are undesirable. Averaging means that it takes longer for recent inflation developments to show up clearly, which may lead to delay in appropriate policy adjustments. In addition, averaging will lengthen the measured delay between policy actions and inflation consequences, weakening the effectiveness of policy accountability.

The effects of calculating inflation at different frequencies are illustrated in Figure 1, using Chilean data. Annualized monthly changes in the CPI are clearly the most volatile, and have frequently moved outside the Bank of Chile's inflation target band. Further, it is difficult to discern major turning points in the series. At the other extreme, the change in the 12-month average has been the least volatile measure, but its turning points lag those of the point-topoint change by about a year.

Figure 1. Chile: Inflation Targets and Outcomes, 1996-2006

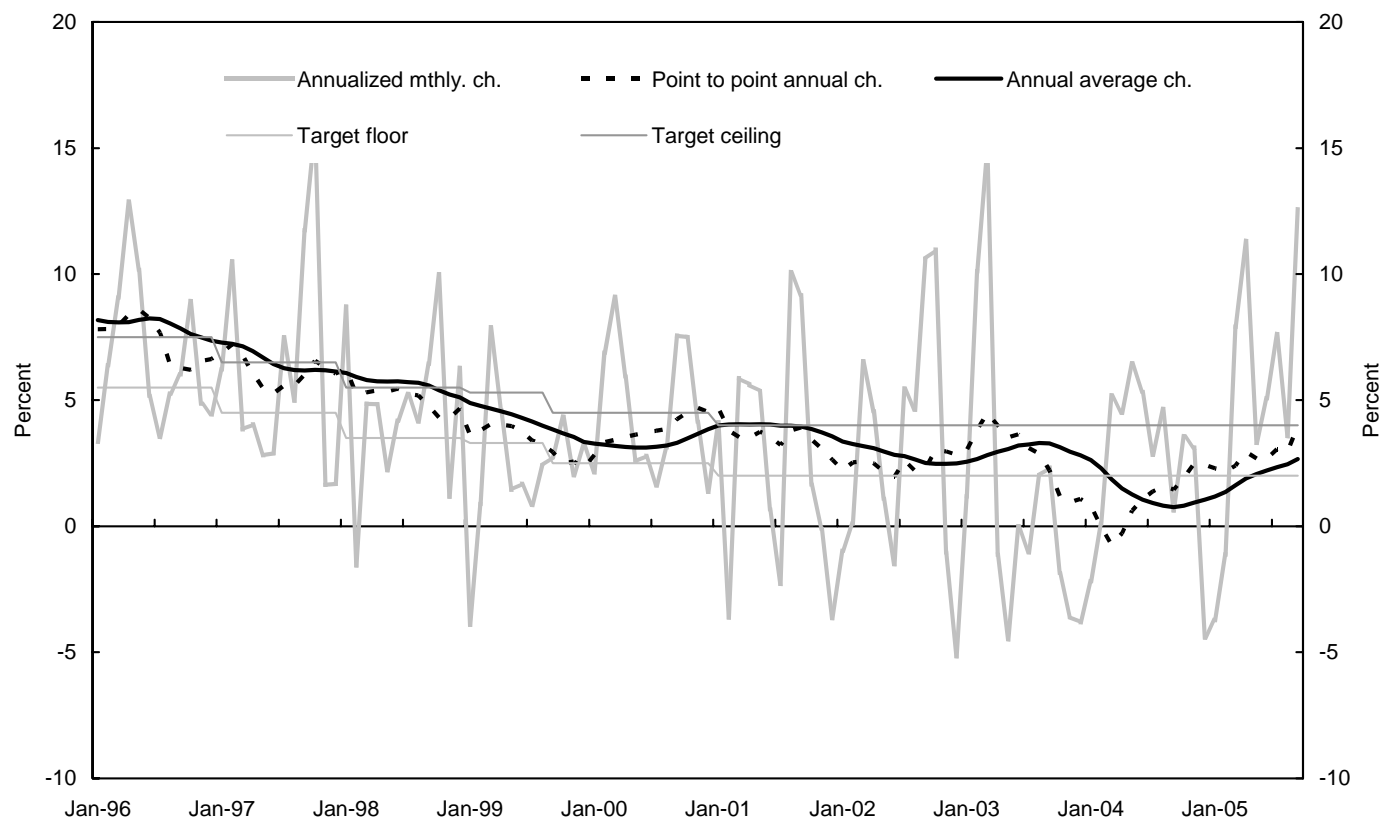


For accountability purposes, it is probably sensible to define the target in terms of the inflation measurement interval most well known to the general public. Generally this will mean using the 12-month point-to-point inflation rate, which strikes a fair balance between timeliness and smoothing. Nonetheless, for internal policy analysis and formulation purposes, it is entirely appropriate for the central bank to monitor (and, if necessary, calculate) higher frequency measures of inflation. In particular, quarterly and monthly seasonally adjusted measures of inflation are highly useful for timely policy analysis.

The central bank and national statistics agency are strongly advised to work together to produce measures of inflation relevant for policy analysis and communications.

Unfortunately, in several countries, development of core inflation measures has been delayed by lack of cooperation between the central bank and the statistics agency, even though such cooperation would be mutually beneficial. Both institutions have expertise that the other lacks, and it is in the ultimate self-interest of the central bank to have core inflation measures calculated and published by the statistics agency rather than by itself. ${ }^{27}$

\section{The Target Rate of Inflation}

Although price stability is the primary objective of most inflation targeting central banks, in practice this has been interpreted in setting targets as a low, positive rate of inflation, rather than a particular path for the price level. The key difference between targeting a price path and an inflation target is that, with a price path target, misses need to be reversed, while under inflation targeting, past misses do not need to be reversed. ${ }^{28}$

Inflation target midpoints and ranges are similar for most countries (Figure 2). For advanced economies the midpoints of targets all fall within a range of 2 to 3 percent, while the targets for emerging market economies are more widely dispersed, though mainly for countries that have not yet completed disinflation. ${ }^{29}$

There is some empirical evidence that low levels of inflation do not have adverse effects on long-term growth. ${ }^{30}$ Estimates for the threshold level of inflation below which inflation is not harmful for growth prospects vary between 1 and 8 percent. Above this threshold, there is clear evidence that growth and inflation are negatively correlated over the long term. This observed relationship may reflect the tradeoff between the costs of inflation, which increase as the rate of inflation increases, and the purported benefits arising from nonzero inflation.

\footnotetext{
${ }^{27}$ The credibility of core inflation measures may be questioned if the central bank itself calculates the measures, especially if the calculations are not readily reproduced or verified externally. Consequently, there is a clear advantage in having such measures calculated independently by the national statistics agency. If the central bank does publish its own core measures, then it should make its methodology public, so that external observers can replicate its calculations. This is the case in Brazil.

${ }^{28}$ See Citu (2002) for a brief review of the issues surrounding price path targeting.

${ }^{29}$ Roger and Stone (2005).

${ }^{30}$ For a review of the theoretical arguments and empirical evidence regarding the relationship between the level of inflation and its associated costs, see Brook, Karegedikli, and Scrimgeour (2002).
} 
Figure 2. Inflation Target Levels and Bands

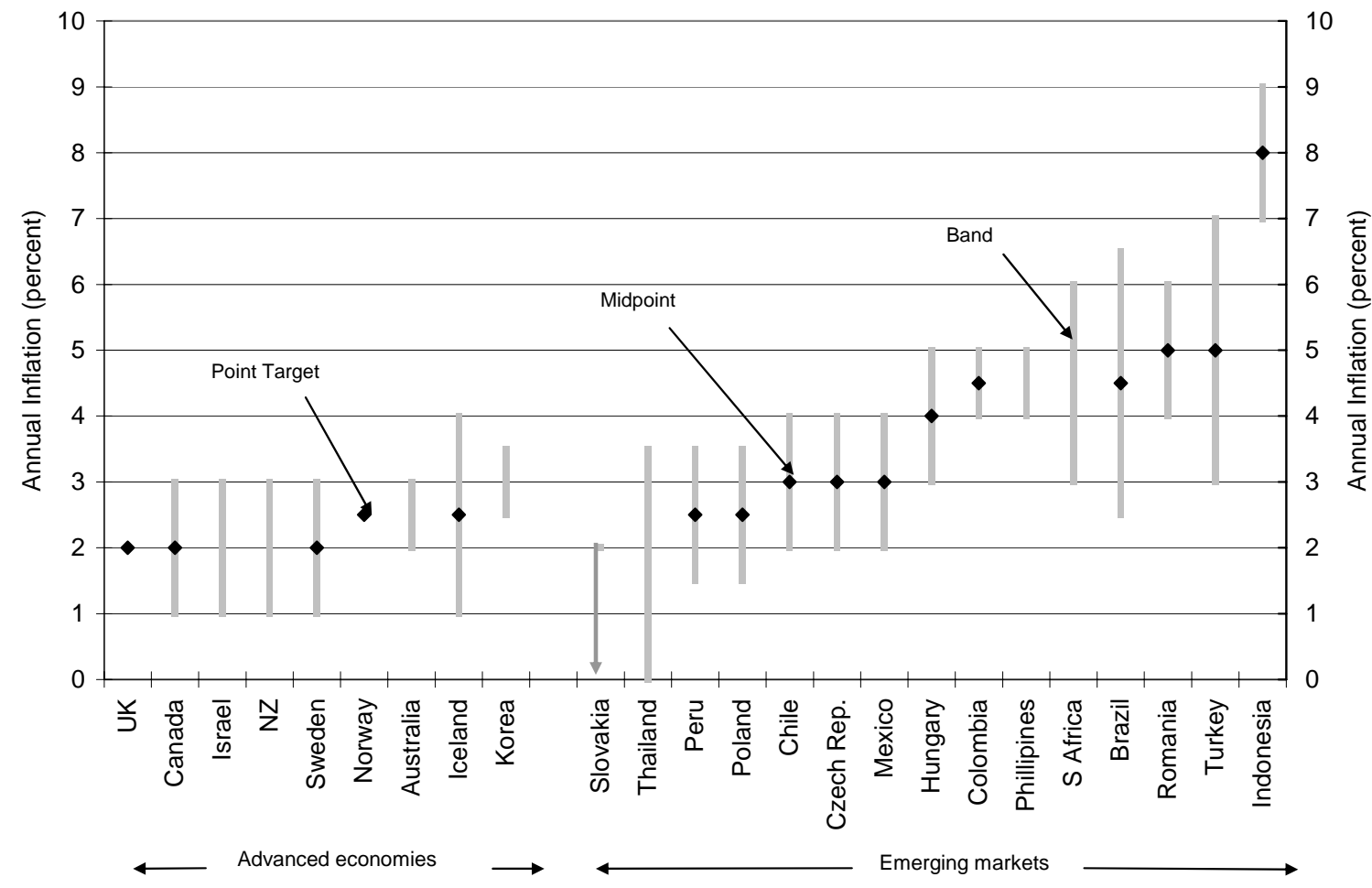

There are several mechanisms by which inflation can adversely affect economic growth over the long term. These include: (i) the interaction of inflation with the taxation system, resulting in the distortion of saving and investment decisions; (ii) inflation variability leading to uncertainty regarding future price levels, again affecting savings and investment; (iii) menu costs associated with the need to adjust prices and wages more frequently in high-inflation environments; and (iv) inflation as a tax on money balances, thereby impeding monetization and intermediation. High inflation could lead to dollarization as people and firms seek to avoid these costs by adopting another currency as a means of payment and as a store of value. These costs increase with the rate of inflation, implying that central banks should target very low, if not zero, rates of inflation.

However, several justifications have been advanced for targeting a low but positive rate of inflation over the medium term: (i) the measured CPI may overestimate actual increases in the price level, for various reasons; (ii) a small positive level of inflation may allow for necessary changes in relative prices and wages in the face of nominal rigidities; (iii) it reduces the probability that nominal interest rates will approach zero, which would render the interest rate channel for transmission of monetary policy ineffective; and (iv) there is reduced risk of deflation.

From a purely economic standpoint, the optimal level of the inflation is an empirical question and will vary from country to country. However, there are political economy considerations 
that suggest that a low but positive level of inflation in line with international experience should be targeted:

- A zero inflation target may lead to a perception of excessively tight monetary policy and fears of deflation. This may undermine the broad political consensus necessary for the successful adoption of inflation targeting.

- On the other hand, too high a target may weaken the inflation-fighting credibility of the central bank.

- An inflation target that is consistent with inflation rates in industrialized countries has the advantage of having no overt implications for movements of the nominal exchange rates vis-à-vis major currencies. Further, it allows the central bank to claim to be implementing inflation targeting according to international best practice.

It is no surprise, therefore, that target levels are broadly similar for inflation targeters that have successfully disinflated.

The choice of a disinflation path is more problematic. Too ambitious a path could lead to an excessive fall in economic activity and concomitant loss of political support for inflation targeting, or may lead to a substantial miss that undermines the credibility of the central bank. On the other hand, too gradual a path may be taken as a lack of commitment by the government and central bank to low inflation, so that the public's inflationary expectations remain high.

Inflation targeters have generally chosen gradual disinflation paths. ${ }^{31}$ Targeted reductions in inflation have been mostly less than 2 percentage points per year. This gradualist approach may reflect two key characteristics of inflation targeting:

- Its successful implementation requires the maintenance of a political consensus regarding its desirability. Too steep a disinflation may result in an erosion of this consensus.

- The flexibility to stabilize output in the short-run inherent in inflation targeting means that adopting central banks must have this as one of their policy objectives, and a gradual disinflation would also be consistent with reducing short-run output fluctuations.

In determining the appropriate disinflation path, the central bank should have an estimate of the sacrifice ratio in order to weigh the costs of forgone output against the benefits of lower inflation. This will tend to be higher in those countries with structural rigidities in their wageand price-setting procedures. However, it is these countries that may have suffered more from persistent inflation, and so the central bank may choose to apply tighter policies despite

\footnotetext{
${ }^{31}$ For a more detailed account of the experiences of inflation targeting central banks with disinflation, see Roger and Stone (2005).
} 
these structural problems in order to disinflate. It is crucial that the announced disinflation path be more ambitious than previous attempts at disinflation, so that it signals a break with previous policies.

\section{The Target Horizon}

There are three time horizons that are relevant in an inflation targeting framework. First, the horizon over which the central bank has committed to numerical targets for inflation. This could involve the specification of a target for the coming year, or a longer disinflation path, or a medium-term commitment to a particular target. Second, there is the forecast horizon, for which the central bank publishes its inflation projections. Lastly, there is the policy horizon, which is the timeframe that the central bank views it can steer inflation in order to achieve its target. This section focuses on the first horizon, the formal target horizon announced by the central bank, but will also touch on the effect of the other horizons in the functioning of the formal target.

While most central banks have low inflation as a long-run objective, inflation targeters must specify a horizon for their commitment to preannounced numerical inflation targets. The choice of target horizon should balance several related considerations:

- To serve as an anchor for inflationary expectations, the horizon should extend to the medium term, at least as long as most people’s economic planning horizons.

- However, medium-term horizons may be less useful in establishing a benchmark for central bank accountability. Since the inflation forecast serves as the operating target in an inflation targeting regime, the horizon should be longer than the lags in the transmission of monetary policy, but no longer than the timeframe for which the central bank could produce meaningful forecasts.

- The longer the horizon, the greater the flexibility available to the central bank to pursue other short-term objectives, such as output or exchange rate stabilization. But a longer horizon may reduce the credibility of the target, especially if the central bank is seen to be pursuing other objectives in the short term. Thus, the length of the target horizon should reflect the preferences of the central bank regarding the trade-off between achieving its inflation target and short-run stabilization.

Having a commitment to low inflation over a medium-term (or indefinite) horizon is not inconsistent with having a shorter horizon for accountability purposes. Even a central bank that has an indefinite target horizon must establish a finite horizon for both its internal and published projections. For example, the RBNZ target of 1-3 percent is to be achieved on average over the medium term, but it must provide an explanation if actual or projected inflation moves outside this band. Therefore, for accountability purposes, the RBNZ seeks to maintain inflation comfortably within the band over the second half of a three-year forward-looking horizon.

Nevertheless, the value of a medium-term commitment to low inflation towards anchoring inflationary expectations is likely to be greater when a central bank has already achieved low 
inflation and enjoys a high level of credibility prior to the adoption of inflation targeting. In that case, a target over a shorter horizon that is consistent with the central bank's long-run inflation objective could fix medium-term expectations if the public believes that the central bank will change not this target from year to year. This is the case in most industrial countries. ${ }^{32}$

In the case of countries with inflation higher than the central bank's long-run objective, many have opted to announce short-term targets to specify the proposed disinflation path. This can be done on a multi-year basis, or annual targets can be set in line with the progress made in reducing inflation.

The characteristics of forecasting models of inflation vary from country to country, but in general response functions to exogenous shocks tend to peak within 12-18 months. This suggests that basing policy decisions on shorter horizons will neglect information on current conditions that is relevant for the future evolution of inflation. On the other hand, over longer horizons, models generally converge to long-run equilibrium or diverge due to misspecification. Therefore, the informational value of forecasts past a two- or three-year horizon is likely to be low, and may in fact lead to erroneous policymaking. This suggests that the policy horizon for internal decision-making and external accountability should be in the range of one to three years.

To conclude, while a central bank may have a medium-term or indefinite commitment for the achievement of its inflation objective, it will also need to specify a shorter horizon for its internal forecasting and decision making, and for external accountability and communications purposes. The horizon should be not shorter than the lags in the transmission of monetary policy and exogenous shocks, but no longer than period for which the central banks can produce informative forecasts. Further, a shorter horizon places greater emphasis on achieving inflation targets rather than short-run output stabilization, and therefore may be more appropriate for countries on disinflation paths.

\section{E. Target Points and/or Bands}

Most inflation targeters have specified a band for their target. Only two countries (Norway and the United Kingdom) have a point target only, while half of those with bands explicitly reference the midpoint as the target. In Norway's case, the point target is approximate only, and applies over a one- to three-year period. This effectively blurs the meaning of the point target. The Bank of England is required to produce a letter to the government if there is a deviation of 1 percentage point from the target. Thus, there is a range of 1-3 percent within which the Bank of England can operate without invoking additional formal accountability procedures.

\footnotetext{
${ }^{32}$ Although Australia's formal commitment is to maintain inflation within 2-3 percent on average over the course of the business cycle, the Reserve Bank of Australia has repeatedly emphasized in its communications that it seeks to keep inflation within this band on an ongoing basis.
} 
There are several reasons to prefer a band, rather than simply a point target:

- A band may more realistically indicate what the central bank can expect to achieve regarding accuracy of its inflation forecasts. No central bank can hope to forecast inflation with complete precision, given uncertainty surrounding the transmission mechanism, and future shocks. Note the two countries with point targets, the United Kingdom and Norway, both include fan charts in their inflation reports to convey the uncertainty regarding their respective inflation forecasts.

- The persistence of inflation, combined with uncertainty regarding the strength and lags of monetary transmission, implies that central banks may be excessively activist if they attempt to achieve a point target continuously.

- A band provides the central bank the flexibility to smooth short-run output fluctuations at the expense of some inflation volatility. In this regard, the band serves a similar purpose to lengthening the target horizon.

- All price indices are subject to measurement and sampling errors. Therefore, by targeting a point, the central bank may react unnecessarily to what amounts to noise in the measurement of inflation.

However, a band may be less effective than a point target in anchoring inflationary expectations, particularly if the central bank makes no commitment to target the middle of the range. This is particularly true for countries that have wide bands. In these cases, the difference between the price levels implied by having inflation at the top of the band compared with the level implied by the bottom of the band can be significant within a two-to three-year horizon.

One possible solution is to define a point target as a medium-term objective, while using a band centered on this point target to define an intermediate target over a shorter horizon. This would provide an anchor for inflationary expectations in the long term, while providing the central bank some scope to accommodate unforeseen shocks and smooth output in the short run.

The role of the band and the midpoint of the target will depend on whether deviations from the midpoint and/or movements outside the band trigger any additional accountability mechanisms or penalties for the central bank. Thus a two-percentage point band that requires a letter to the government if breached may represent a tighter constraint than a 1 percentage point band that carries no such requirement.

The most common width for bands is 2 percentage points, though wider bands are more prevalent among recent adopters. A wider band reduces the risk of a breach due to an unforeseen shock or errors in the modeling of inflation and the transmission mechanism. Therefore, a central bank could choose a wider band to reflect greater uncertainty regarding inflation outcomes, if the economy was subject to greater exogenous shocks, or the accuracy of inflation projections was limited by a lack of data or forecasting capacity. However, a wider band could detract from the credibility of the central bank, especially if it is wider than 
the historical volatility of inflation over the target horizon. In addition, if a core measure of inflation is specified as the target, or escape clauses are used, there would be less justification for selecting a wider band.

\section{F. Escape Clauses}

Escape clauses are events that are specified ahead of time and would justify deviations of inflation from the target. Their use is not widespread, with only five inflation targeting countries having specific exceptions in their target definition. The most common escape clause specified has been with regard to the effect of changes in administered prices or indirect taxes. Less frequently, escape clauses have dealt with the movements of highly volatile components of the CPI, such as petroleum and food. However, most countries have chosen to deal with volatility by using a core measure that excludes these items.

There may be limited advantage in having escape clauses to deal with exogenous shocks, such as administered price or tax increases or large changes in energy prices. The central bank would have to explain the impact of such shocks, its policy response, and the projected inflation path whether or not there was a formal escape cause. However, the presence of an escape clause could allow the central bank to educate the public about these shocks ahead of time. Nevertheless, formal escape clauses may be overly legalistic in their formulation, which then could distract the public communications of the central bank from the underlying macroeconomic issues and towards the technical details of the escape clause itself.

\section{Monetary Policy Communications ${ }^{33}$}

\section{A. The Role of Policy Communication Activities}

Public communication activities are a key component of inflation targeting frameworks. Inflation targeting central banks typically put much more effort into explaining policy issues and decisions, as well as being more open about central bank operations and research, than central banks with more traditional frameworks. ${ }^{34}$ The emphasis on openness or transparency in the formulation and implementation of policy reflects a number of considerations:

- A normative argument that, as a public institution, if the central bank is given a high degree of operational independence to pursue inflation targeting, this should be matched by a correspondingly high standard of public accountability and transparency;

\footnotetext{
${ }^{33}$ Blinder and others (2001) provide an excellent review of monetary policy communications issues. Although the emphasis is on industrial countries, the discussion of most issues is relevant to all central banks, not only those pursuing inflation targeting.

${ }^{34}$ See, for example, IMF (2005).
} 
- The view that the efficiency of monetary policy depends heavily on the credibility of the central bank's commitment to the inflation target and public perceptions of the consistency of the central bank's actions with its declared objectives; ${ }^{35}$

- The recognition that policy transmission lags are generally long, so that careful explanation is needed to distinguish between the effects of monetary policy and other influences on inflation;

- The need to explain clearly and credibly how considerations other than inflation are factored into decision making, especially in flexible inflation targeting frameworks, in a manner consistent with achieving the inflation target over the medium term. ${ }^{36}$

The evolving literature on transparency in monetary policy distinguishes between different kinds of transparency. Hahn (2002) proposes a three-fold distinction between goal transparency, focusing on the clarity of the central bank's mandate and policy objectives; knowledge transparency, focusing on the data and analysis underlying policy decisions; and operational transparency, focusing on the clarity of the policy decision-making process and policy implementation. ${ }^{37}$ Although these distinctions are not always very clean in reality, they are still useful. In this section, the main focus is on knowledge and operational transparency, as goal transparency is largely covered in the earlier discussion of inflation target design.

\section{B. Audiences, Objectives, and Modes of Central Bank Communication}

Blinder and others (2001) emphasize the need to take a strategic approach to central bank communication. The central bank needs to identify key groups or audiences for its communications, and its objectives vis-à-vis these groups. In addition, the most appropriate means of interaction or communication to achieve the particular objectives also varies according to the audience. A key point of Blinder's discussion is that virtually all of the central bank's objectives vis-à-vis its various audiences will be best served by a high degree of transparency. Table 5 summarizes the variety of audiences, objectives, and modes of communication involved in a standard communications program of an inflation targeting central bank.

\footnotetext{
35 The incorporation of the importance of the notions of consistency and credibility into the core of the inflation targeting framework reflects the incorporation of expectations into monetary policy analysis. Of particular importance in this regard are Lucas $(1972,1976)$, emphasizing the role of expectations in determining the effectiveness and transmission of monetary policy; and Kydland and Prescott (1977) and Barro and Gordon (1983) on rules versus discretion and inconsistency of optimal policy over time. For a more recent view of the importance of communications in increasing policy effectiveness under inflation targeting, see Woodford (2005).

${ }^{36}$ Edwards (2004) warns that, otherwise, there is the risk that more flexible inflation targeting could reduce to “... a ‘checklist approach,' in which the weight and priority and urgency of various goals is undefined.”

${ }^{37}$ Carpenter (2004) offers a similar taxonomy, while Eijffinger and Geraats (2002) use a five-fold taxonomy.
} 


\section{Audiences}

Blinder and others (2001) identify four broad external audiences for the central bank: the general public and mass media; the government and legislature; financial market participants; and expert central bank "watchers." Such groups are distinguished by different needs and interests with regard to the central bank and monetary policy, as well as by differences in understanding of monetary policy issues.

The press and central bank "watchers" may be particularly important audiences in nonindustrial countries. The press and central bank "watchers”-including academics, analysts in think tanks or financial institutions, and journalists specializing in finance or economics_-play an important role in intermediating and filtering information between the central bank and audiences with relatively low levels of knowledge of macroeconomics and monetary policy issues. This role may be especially important in nonindustrial countries, where general public knowledge of monetary policy and macroeconomics may be lower than in industrial countries. Although, as Blinder and others (2001) note, the central bank needs to be careful to maintain an arm's length relationship, it should be prepared go to considerable lengths to encourage development of a group of well-informed central bank "watchers" and to facilitate their efforts to educate the wider audience, even if the watchers do not always agree with the central bank's policies.

In some countries, particular problems may arise from the lack of an independent media. In such circumstances it is especially important for the central bank's communications efforts to reach out to members of all major political parties (for example in background briefings), as well as to the various partisan media. So far as the content of the central bank's policy messages are concerned, it is essential to stress the nonpartisan nature of the monetary policy framework and decision making, and to explain in as simple terms as possible some of the basic concepts underlying the policy framework. These efforts will not, of course, eliminate partisanship, but the aim should be to establish some common ground and understanding in the key areas underpinning the framework, and why it is in the longer term interest of all parties to de-politicize monetary policy.

For emerging market and developing countries, the international audience is also very important. In many cases, international investors, portfolio managers, foreign exchange strategists, and so on, may not be well informed on the inflation targeting regime being put into place. As a consequence, capital flows may be more volatile than if such investors were better informed. 
Table 5. Audiences, Objectives, and Modes of Communication

\begin{tabular}{|c|c|c|}
\hline Audiences & Objectives & Modes of Communication \\
\hline \multirow[t]{8}{*}{$\begin{array}{l}\text { General public and } \\
\text { media }\end{array}$} & $\begin{array}{l}\text { Promote understanding and support for low } \\
\text { inflation as primary focus of monetary policy }\end{array}$ & Speeches and unofficial presentations \\
\hline & $\begin{array}{l}\text { Ensure that reporting and debate on } \\
\text { monetary policy issues is well-informed }\end{array}$ & $\begin{array}{l}\text { Inflation Report, press releases and minutes of policy } \\
\text { meetings }\end{array}$ \\
\hline & & Press conferences \\
\hline & $\begin{array}{l}\text { Promote confidence in competence and } \\
\text { trustworthiness of central bank }\end{array}$ & Interviews \\
\hline & & Brochures and educational materials for schools \\
\hline & & Regional visits \\
\hline & & $\begin{array}{l}\text { Website provision of information on central bank mandate } \\
\text { and governance arrangements, transmission mechanism, } \\
\text { policy formulation, instruments and operations }\end{array}$ \\
\hline & & Responding to public letters, e-mail, telephone calls \\
\hline \multirow[t]{4}{*}{$\begin{array}{l}\text { Government and } \\
\text { legislature }\end{array}$} & $\begin{array}{l}\text { Promote independence of central bank from } \\
\text { partisan politics through transparency }\end{array}$ & Speeches and unofficial presentations \\
\hline & $\begin{array}{l}\text { Promote understanding and support for low } \\
\text { inflation as primary focus of monetary policy }\end{array}$ & $\begin{array}{l}\text { Inflation Report, press releases and minutes of policy } \\
\text { meetings }\end{array}$ \\
\hline & & Testimony to parliamentary committees \\
\hline & $\begin{array}{l}\text { Ensure that reporting and debate on } \\
\text { monetary policy issues is well-informed }\end{array}$ & $\begin{array}{l}\text { Background briefings to government officials and } \\
\text { legislators on policy and operational issues }\end{array}$ \\
\hline \multirow[t]{5}{*}{ Financial markets } & $\begin{array}{l}\text { Ensure that market participants are fully and } \\
\text { simultaneously informed of any adjustments }\end{array}$ & Preannounced schedule of policy announcements \\
\hline & in policy instruments & $\begin{array}{l}\text { Inflation Report, press releases and minutes of policy } \\
\text { meetings }\end{array}$ \\
\hline & $\begin{array}{l}\text { Ensure that reporting and debate on } \\
\text { monetary policy issues is well-informed }\end{array}$ & $\begin{array}{l}\text { Rapid wire-service release of all major announcements } \\
\text { and clear explanation of policy actions }\end{array}$ \\
\hline & $\begin{array}{l}\text { Promote good understanding of Central } \\
\text { Bank's approach to policy formulation and } \\
\text { risk assessment to maximize policy } \\
\text { predictability }\end{array}$ & $\begin{array}{l}\text { Briefings/presentations to FX strategists and portfolio } \\
\text { managers in major international financial centers }\end{array}$ \\
\hline & & Consultation on modifications to operational framework \\
\hline \multirow{5}{*}{$\begin{array}{l}\text { Central bank } \\
\text { "watchers" in media, } \\
\text { academia, and } \\
\text { financial markets }\end{array}$} & $\begin{array}{l}\text { Promote understanding and support for low } \\
\text { inflation as primary focus of monetary policy }\end{array}$ & $\begin{array}{l}\text { Inflation Report, press releases and minutes of policy } \\
\text { meetings }\end{array}$ \\
\hline & $\begin{array}{l}\text { Promote good understanding of central } \\
\text { bank's approach to policy formulation and }\end{array}$ & Publication of research on monetary policy issues \\
\hline & $\begin{array}{l}\text { risk assessment to maximize policy } \\
\text { predictability }\end{array}$ & Briefings on technical and policy issues \\
\hline & $\begin{array}{l}\text { Ensure that reporting and debate on } \\
\text { monetary policy issues is well-informed }\end{array}$ & $\begin{array}{l}\text { Seminars, workshops, conferences, visiting scholar } \\
\text { programs to share knowledge and research }\end{array}$ \\
\hline & $\begin{array}{l}\text { Promote university level research and } \\
\text { training on monetary policy issues }\end{array}$ & $\begin{array}{l}\text { Website provision of detailed information on central bank } \\
\text { mandate and governance, arrangements, transmission } \\
\text { mechanism, policy formulation, instruments and } \\
\text { operations, together with publications and relevant data. }\end{array}$ \\
\hline
\end{tabular}




\section{Objectives}

In an inflation targeting framework, communications activities focus on two principal objectives: ensuring broad support for the policy framework, and enhancing the credibility and effectiveness of policy. Even if the central bank has a strong formal mandate for the pursuit of low inflation, general public support for the policy goal and the inflation targeting framework will strengthen the effective mandate, as well as help the central bank to resist pressures to pursue other objectives.

Building or maintaining support for the framework typically involves a number of elements, including:

- Explaining the key elements of the framework, including the accountability and transparency requirements, and the specification of the target. An especially important aspect of the communications task is the need to promote understanding of the benefits of low inflation and to give achievement of the inflation target priority over other objectives over the medium term;

- Educating the public on the monetary policy transmission mechanism, the limits of policy, and how the central bank addresses policy trade-offs or conflicts. This is aimed at promoting informed debate and understanding of monetary policy issues;

- Demonstrating the central bank's commitment to take into account all relevant information, as well as views on key trade-offs that may be involved in policy formulation. This necessarily requires an ongoing dialogue with a wide range of interest groups—including critics - to ensure that the central bank's approach to policy formulation is appropriately adapted to domestic circumstances, as well as to promote widespread understanding of the limitations of monetary policy in addressing sector-specific concerns.

Effective implementation of monetary policy, including inflation targeting, depends heavily on the central bank's ability to influence expectations and decision making across the economy. Essentially, this requires convincing economic agents, notably including financial market participants, price and wage setters, as well as the fiscal authorities, that policy formulation and implementation is consistently oriented toward achieving the inflation objective. Typically, the largest part of the central bank's external communications is geared towards this objective. Major elements include:

- Regular reporting on inflation outcomes relative to the target. This aspect of accountability is particularly important when inflation outcomes differ significantly from the inflation target or target range. The key objective is to distinguish between significant discrepancies resulting from exogenous events and those resulting from policy errors;

- Regular reporting on economic developments, their implications for inflation pressures, and assessment of the appropriate monetary policy response. This analysis 
is necessarily forward looking, and plays an important role in informing financial market expectations;

- Prompt reporting of monetary policy decisions and actions, clearly linked to analysis of prospects for inflation, and showing a consistency of approach to policy decisions over time in order to maximize the predictability of policy adjustments to news;

- Frequent meetings with and presentations to a wide range of audiences, focusing on the formulation and implementation of the inflation targeting strategy. Such meetings and presentations provide the central bank with the opportunity address particular issues or to tailor its discussion of general issues to particular audiences. They can also provide the opportunity for more two-way communication and discussion.

\section{Modes of communication}

The appropriate form of central bank communication depends both on the nature of what is being communicated and on the nature of the audience. Consequently, a wide range of methods will normally be used, including:

- Published documents. These include Monetary Policy or Inflation Reports, Statistical Bulletins, Annual Reports, published minutes of meetings of the monetary policy decision-making committee, special reports and public letters, research and discussion papers, press notices, and pamphlets;

- Public presentations. These include public speeches, formal appearances before governmental committees, press conferences, press interviews, as well as participation in conferences, regional visits, and other public appearances where there is press attendance;

- Unofficial presentations. These include unofficial speeches or remarks and participation in conferences, seminars, and workshops by senior central bank staff, as well as briefings or round table meetings with various groups, not open to the general public or press;

- Educational activities. Many central banks have museums open to the public and host school visits. A number also provide educational materials on monetary policy to schools. A few (e.g., New Zealand) also organize monetary policy competitions or contests between high schools.

- Central bank website. Central bank websites play an increasingly important role in making a wide range of central bank material available to all types of audiences. An important feature that distinguishes this mode of communications from almost all others is that it is user initiated, and therefore needs to be geared to meeting very different kinds of needs; 
- Direct correspondence with members of the public. Most central banks devote some resources to responding to letters, e-mails, or calls from members of the public seeking information or expressing views.

\section{Managing Central Bank Communications}

The importance and complexity of central bank communications activities highlights the need to develop a comprehensive communications strategy and to carefully manage its implementation. Curiously, however, this basic element of an inflation targeting framework tends to be neglected in central banks' preparations for inflation targeting. ${ }^{38}$ Moreover, relatively little has actually been published by central banks on their communications efforts or management. ${ }^{39}$ The discussion in this section, therefore, relies heavily on advice provided on communications issues provided during MCM technical assistance missions and through discussions with senior communications managers in a number of central banks with strong reputations for transparency and effective communications.

A dedicated communications department or unit is essential for planning and managing the wide range of communications activities. Given the range of different communications objectives and audiences, a well-thought-out strategy covering all aspects of the central banks external communications and relationships is needed to ensure that these efforts are carried out in an efficient and effective manner. Monitoring and review of the implementation of the communications strategy is also required. In addition, the implementation of the communications strategy involves a substantial logistical task, demanding specialized skills. The strategic and operational tasks are best managed by a single unit staffed by experienced communications professionals.

In most central banks, such units work extremely closely with the most senior central bank personnel. Senior personnel spend a great deal of their time on communications actives, including frequent speeches, presentations, briefings and interviews, regional visits, and meetings with various interest groups or business associations, in addition to their involvement in preparing the central bank's main written policy communications activities and participation in external meetings. To be able to perform these tasks efficiently and effectively, senior staff need ready access to professional assistance. At the same time, the communications unit needs to be very well informed on policy issues so as to be able to handle media queries, as well as to be able to advise senior staff on communications. Last but not least, the communications strategy needs to be adapted to the personalities of the senior management, so that the senior communications staff need to know their “clients” well. For

\footnotetext{
${ }^{38}$ As noted in Batini and others (2006), over half of the IMF's technical assistance on inflation targetingwhich is largely demand-driven — has been on forecasting and data analysis, while communications, data, and target specification each accounted for about 10 percent.

${ }^{39}$ On communications issues, staff at central banks may prefer talking to each other than explaining their craft to the public_conferences and workshops on central bank communications are fairly common now (e.g., the High Level Central Bank External Communications Seminar hosted by the CCBS, London, in October 2005, the $10^{\text {th }}$ CEMLA meeting on Communications, hosted by the Central Bank of Chile, Santiago, in November 2005, and the IMF Regional Seminar on Central Bank Communications held at Mumbai, in January 2006). Publications are much rarer, such as Jackman (2002).
} 
these reasons, the communications unit or its senior officers are usually located close to the senior management's offices and participate (generally as observers) in policy meetings. It is also common for a high-level committee to be established in the bank to plan and review communications activities on a regular basis.

Management of communications activities typically distinguishes between strategic or policy elements and operational implementation. Within the communications unit, it is common to establish a group or sub-unit working very closely with the governor and other senior staff, and focusing on strategic and policy aspects of communications, including:

- Working with senior management to design and plan a comprehensive program of communications activities;

- Identifying key issues and audiences and advising management on how to address these effectively;

- Providing guidelines to staff and management on external communications;

- Assisting management with preparation of the content of speeches, interviews, press conferences, statements, etc.;

- Handling media enquiries and relationships with the media and analysts;

- Designing and handling education programs;

- Monitoring or review of the effectiveness of communications;

- Responding to correspondence from the public.

Operational implementation aspects of communications cover a wide range of activities requiring specialist skills. These activities include:

- Editing and translation of documents;

- Desktop publishing and graphics for major documents, PowerPoint presentations, pamphlets, etc.;

- Managing the logistics of press conferences, speeches, meetings, conferences, regional visits, etc.;

- Designing and maintaining the central bank's website.

\section{Reporting on Policy Decisions and Performance}

The core communication activities under inflation targeting focus on explaining policy decisions and accounting for performance relative to the explicit inflation objective. These activities involve, in particular, reporting on regular meetings to review and adjust the stance 
of policy, and the keystone role of Monetary Policy or Inflation Reports, including their content, production, and associated activities.

\section{Regular reporting on policy decisions}

\section{Announcements of policy decisions}

It is becoming standard practice to establish and publish a schedule of regular policy decision-making meetings. ${ }^{40}$ Preannouncing a schedule of meetings, focused specifically on adjustments in the policy stance, is a relatively recent innovation, but has quickly become a standard element of good practice not only in inflation targeting central banks but more generally. For the central bank this facilitates planning the work in advance of, as well as following, such meetings. For financial market participants, analysts, and the media it is also very helpful to know that adjustments in the central bank's policy stance will only take place (except in extraordinary situations) on the pre-announced dates, minimizing the potential for confusion regarding interpretation of tactical actions by the central bank. This may be particularly important if the central bank is active in the foreign exchange market, where actions could be misinterpreted as policy signals. In such circumstances, it is especially important that the central bank make very clear that adjustments in the policy stance will only occur on the pre-announced dates. Of course, the credibility of this commitment also requires that the central bank stick to the calendar. ${ }^{41}$

Meetings to review and adjust policy settings are normally synchronized with the forecasting schedule. ${ }^{42}$ Macroeconomic forecasts are typically produced on a quarterly basis, following the release of quarterly national accounts data, and play a major role in policy decision making. In particular, the forecasts can help in assessing the implications of economic developments for inflation and the monetary policy stance in a comprehensive and systematic manner. The time needed to generate new macroeconomic forecasts following national accounts data releases, together with the timing of CPI releases, can be used to pin down a schedule of policy reviews. ${ }^{43}$

Meetings to review the appropriate stance of monetary policy are usually held 8-12 times per year. ${ }^{44}$ As a consequence, between each policy reassessment based on a full forecast, there

\footnotetext{
40 Typically the schedule is announced annually, and posted on the central bank website, as well as in the inflation report or other policy document. It is also common, in the press statement following such meetings, to remind readers of the date of the next meeting.

41 This also implies that, as a general rule, the central bank should largely sterilize foreign exchange market intervention, since unsterilized intervention is, effectively, monetary policy.

${ }^{42}$ Laxton and Scott (2000) provide a thorough discussion of the role of forecasts in the policy making process, including the synchronization of data releases, forecast stages, and decision making. Canales-Kriljenko and others (2006) discuss the development of the forecasting capacity.

43 The central bank may wish to avoid having policy meetings immediately before scheduled CPI release dates, in order to avoid having some decisions become obsolete very quickly.

${ }^{44}$ Meetings to review recent economic and financial developments, and to make more "tactical” decisions on policy implementation would normally be held more frequently (daily or weekly).
} 
will be one or two meetings involving a somewhat less comprehensive reassessment of recent developments and the implications for the outlook. Even in the absence of a full set of forecasts, however, central bank staff normally prepare briefing materials providing a review of recent economic developments, together with a partly qualitative assessment of how these might change the inflation outlook and the risks in the outlook, and what this might imply for the appropriate stance of policy. An important feature of such inter-forecast policy reviews is that the most recent set of comprehensive forecasts are usually used as a benchmark in evaluating new information. This provides an important element of consistency and continuity between successive policy reviews.

Inflation targeting central banks communicate policy decisions in a variety of ways. As indicated in Blinder and others (2001) and Blinder and Wyplosz (2004), the character of the monetary policy decision-making committee may affect the way in which additional information on policy decisions are communicated. In countries where policy decisions are made by consensus or by the governor on the advice of a committee, it may be relatively easy to come up with an agreed text for a statement following a policy decision. In countries with a more individualistic, vote-based, approach to policy decision-making, it may be difficult to reach agreement quickly on a statement text, in which case publication of minutes may be the preferred mode of communication. In practice, the main approaches include:

- The most common approach is for the central bank to provide a statement of 1-2 pages, describing the policy decision simply and precisely, and also providing a brief review of recent developments and explaining the basis for the policy decision. Once per quarter, the policy statement would be supplemented by the publication of an inflation report providing a comprehensive review of economic and financial developments and the implications for inflation pressures and monetary policy;

- In a few countries (Brazil and the United Kingdom), the statement is limited to announcing the policy actions, with no explanation. At a later date, however, minutes of the policy meeting are published, which explain the basis of the decision. As with the first approach, the statement of the policy decision is accompanied by the release of a full inflation report on a quarterly basis;

- Several other central banks provide both a 1-2 page statement summarizing the decision and the basis for it, and also provide supplementary information (in addition to the inflation report). Bank Indonesia, for example, publishes a Monetary Policy Review as background to its monthly policy statement in the months when a full inflation report is not released. Norges Bank supplements its statements with a package of charts used in the policy meetings. The Czech, Israeli, Philippine, and Swedish central banks supplement their policy statements with later publication of minutes of meetings;

- In some countries (e.g., Iceland, Norway), the release of the policy decision is accompanied by a short press conference at which the basis of the policy decision is explained. 
Much of the background material underpinning policy decisions, whether published in statements or in minutes of policy meetings, is similar. This reflects the fact that monetary policy decision-making committees in most inflation targeting countries go through similar processes to review recent macroeconomic and financial data and need to weigh uncertainties and risks in coming to decisions. All countries provide a description of the key macroeconomic and financial developments since the previous policy meeting. Many also relate these developments to forecasts for future inflation. Many also have some discussion of major risks or uncertainties. Only a few, however, discuss explicitly the likely direction of future adjustments in policy settings.

Differences between reports on policy decisions mainly involve the use of forecasts in communications, and the degree of candor in explaining how various risks and uncertainties are weighed up in reaching policy decisions. In a number of countries (e.g., Czech Republic, New Zealand, and Norway), model-based forecasts figure prominently in the quarterly Inflation Reports, and so it is natural for inter-forecast reports to use these forecasts as explicit reference points. In other countries, which are much less explicit about their forecasts, it is more difficult to use earlier forecasts as benchmarks for discussion of recent economic developments. Similarly, with regard to discussion of how policymakers take risk and uncertainties into account in policy decisions, countries that are more explicit in their discussion of these tend to be countries that deal with the uncertainties more explicitly in their forecasting processes, so that the exercise of judgment is clearer to those involved in decision making. In countries that formulate policy with less use of model-based forecasts, or where several models may be used, it may be more difficult to identify and describe how policy decisions take risks and uncertainty into account.

\section{Minutes of policy meetings}

Views are mixed on publishing minutes of monetary policy decision-making meetings. The IMF (1999) Code of Good Practices on Transparency recommends publication of minutes of the policy meetings, but it has not yet become standard practice. Currently, only seven inflation targeters (Brazil, Czech Republic, Hungary, Israel, Philippines, Sweden, and the United Kingdom) publish minutes of policy meetings. One reason may be that many central banks believe that publication of minutes would add little to their current explanations of policy decisions. In addition, some central banks may be concerned that publishing minutes could inhibit open discussion in such meetings. Blinder and others (2001), however, argue that minutes are not transcripts, and can be written to focus on the issues being debated, and indicate balances of views, without identifying where individuals stood on particular issues. This is, in fact, how most sets of minutes are written. Moreover, of those countries where votes on decisions are reported, most report only the balance of opinion, while only two central banks (Hungary and the United Kingdom) report individual votes. If minutes are published, and especially if the announcement of the policy decision provides little background, then it is best to release the minutes as soon after the policy announcement, and well before the next policy meeting. In most countries, the minutes are released within two weeks, but in the Philippines they are released with a one-month lag.

Minutes can provide helpful insights into the way in which the policy decisions are made, at least if the minutes go beyond what is made immediately available in a statement following 
the policy decision. Publication of minutes provides an opportunity for the decision-making committee to show that it takes into account a wide range of information in addition to any forecasts and analysis of the central bank staff, and does not process this information in a mechanical fashion. An excellent example of this provided by the minutes of the Swedish Riksbank meetings. In most countries, the minutes devote a substantial proportion of the document to simply describing recent developments. In the Riksbank minutes, however, the presentation of the facts is kept short, but there is an extensive discussion of how the data should be interpreted and whether developments are consistent with the forecasts. The important point here is that minutes presented this way present a much more accurate picture of the uncertainties and responses to those uncertainties than can be presented in a very short statement. At the same time, the minutes should be careful to avoid giving the impression that the policy discussion is disorganized, or that differences in views reflect lack of commitment to the inflation objective. This may be especially important in countries with little initial policy credibility, or where there may not be very experienced central bank "watchers" in the media, academia, or the financial sector.

The release of policy decisions needs to be handled consistently and with appropriate security procedures. Policy decisions move markets. To avoid favoring any particular individuals or being accused of corruption, it is important to establish arrangements to avoid leaks and make sure that the announcement is released simultaneously to all market participants. To do this, the central bank can give advance notice to the press and financial market participants as to exactly when and how the announcement will be released.

Commonly, the central bank will place its announcement onto one of the major wire service pages directly, send out batch e-mail notices, and simultaneously post the policy decision on its website. If a press conference is held, the announcement of the policy decision should be synchronized with the electronic release. Web-casting of the press conference is a further step that can be taken to provide widespread, simultaneous access to the policy announcement. The precise timing of a release normally takes into account both the needs of the financial markets and the decision-making process itself. One example is the European Central Bank (ECB) schedule, which appears to have been emulated by a number of other central banks. With this schedule, the policy decision makers meet the afternoon prior to the policy decision to receive relevant analysis and briefings from ECB staff. The following morning the board meets again to come to a policy decision, which is announced at 2:00 p.m., accompanied by a press conference to explain the decision. In the cases of Iceland and Sweden, the policy decision is announced the morning following the policy meeting.

\section{The Monetary or Inflation Report}

The Monetary or Inflation Report is the primary vehicle for the central bank to provide both forward- and backward-looking policy transparency and accountability. It provides a regular and formal means for reporting on how inflation has evolved relative to the target and relative to what was expected by the central bank. The Report also serves a forward-looking accountability role by providing a detailed discussion of the current state of the economy, the outlook for inflation and attendant risks, and a judgment on the appropriate stance of monetary policy based on the information and analysis at hand. 


\section{Content of the Inflation Report ${ }^{45,46}$}

Monetary Policy or Inflation Reports in most countries involve some standard elements, although they may vary somewhat in the organization, style, level of detail, and candor of the material. The standard elements include:

- Reviews of recent inflation, activity, and financial developments. These serve two main purposes. First, they provide retrospective accounting for inflation outcomes. Second, they provide a characterization of the macroeconomic and financial market background underlying the discussion of the outlook for inflation.

- A forward-looking discussion of the main factors driving the outlook for activity and inflation over the period relevant for policy decisions (typically at least two years). This discussion will usually be based on the central bank's own forecasts, but can also include market forecasts and expectations surveys. The discussion of the outlook almost certainly requires presentation of a forecast path for inflation, but the amount of additional forecast detail can vary from very little to a great deal.

- A policy discussion of the main areas of risk or uncertainty in the economic outlook and their implications for the appropriate current and future stance of monetary policy.

- A summary and policy decision or recommendation based on the policy discussion.

- A number of "boxes" focusing on specific economic or technical issues.

- Annexes providing more detailed data, a record of previous policy statements, a description of key features of the policy framework, etc.

In some cases the policy discussion and decision may be published separately from the Inflation Report. ${ }^{47}$ Separation may be appropriate if the policy decision-making body (the board or MPC) uses the Inflation Report as an input to its decision making, but without endorsing the analysis. This distinction may be important if the decision-making body is largely comprised of persons from outside the central bank. Conversely, if the decisionmaking body is mainly made up of central bank staff, it is probably more appropriate to include the policy discussion and conclusions in the Inflation Report to underscore that the decision makers endorse the substance of the analysis in the Report underlying the policy conclusions.

\footnotetext{
${ }^{45}$ See Fracasso, Genberg, and Wyplosz (2003) for an excellent and very useful discussion of the content and comparative strengths of Inflation Reports.

${ }^{46}$ See Appendix 1 for a more detailed discussion of the contents and production of the Inflation Report.

${ }^{47}$ Until quite recently this was the case in Norway.
} 
There may also be logistical reasons for publishing the policy assessment and decision ahead of the full Inflation Report. The full Report may take up to a week to finalize and publish, but the policymaking body of the central bank may wish to announce and implement its decision within a day of making the decision. In this case, the key sections of the Inflation Report could be issued in advance, but also be included in the full Report, for completeness. ${ }^{48}$

\section{Production of the Inflation Report}

The production of the Inflation Report needs to be closely synchronized with forecasting and policy decision-making processes. In most inflation targeting countries, comprehensive reassessments of the outlook for inflation and the appropriate stance of monetary policy are conducted quarterly, following the release of quarterly national accounts information. Inflation Reports, reflecting that reassessment, need to be prepared in tandem with the preparation of the economic forecasts, and the release of the finalized Inflation Report needs to closely follow the final policy assessment and decision on the adjustment of policy settings. Many of the people involved in preparation of the forecasts will also need to be involved in the preparation of the Inflation Report. Consequently, the forecasting, decisionmaking, and Inflation Report writing timetables need to be worked out together. ${ }^{49}$

The production cycle for Inflation Reports does not have to be strictly tied to the forecasting cycle. Although forecasting cycles are typically quarterly, Inflation Reports can be produced at a different frequency. Central banks with relatively limited resources could consider adopting the Bank of Canada's approach of publishing a full Inflation Report only twice per year, with more limited "updates” published mid-way between. The Hungarian central bank has also moved to a twice-yearly full report with intermediate updates, following the shift from annual inflation targets to a medium-term target. It is argued that with the lengthening of the policy horizon, less frequent full reviews are needed. This approach would also be appropriate if a full reassessment of the forecasts was also only undertaken semi-annually.

The main text of the Inflation Report needs to be understood by a nontechnical style aimed at a broad audience. Given the importance of the Inflation Report for central bank accountability to the public at large, it needs to be understandable to a broad range of readers with only limited familiarity with macroeconomic theory or terminology. The main text needs to focus on the broad forces driving activity and inflation, based on a clear and coherent portrayal of the policy transmission mechanism. More technical issues can be tackled in "boxes" or annexes. Graphs and tables should also be used extensively to complement text and to reduce the need to clutter the text with numbers.

Development of an Inflation Report can draw extensively on existing publications. Almost all central banks produce Annual Reports, as well as monthly or quarterly statistical reports, including sections reporting on recent macroeconomic, financial, or balance of payments

\footnotetext{
${ }^{48}$ See, e.g., the Brazilian Inflation Report.

${ }^{49}$ Laxton and Scott (2001) provide, among other things, an excellent guide to setting up a timetable for the inflation forecasts and policy decisions. Production of the Inflation Report needs to be worked around such a timetable.
} 
developments. The technical skills and software involved in preparing the text, tables, charts, layout, as well as editing, printing, distribution, and other requirements of a professional publication can be readily adapted to the needs of an Inflation Report. If these do not exist, or are insufficient, the central bank will need to develop them. In any event, it will often be cost-effective to bring in external consultants to advise on the design of the inflation Report, as well as on technical aspects of publishing to ensure that the process is as efficient as possible.

As the Inflation Report and other documents in support of inflation targeting are developed, older documents need to be cut back and refocused. In particular, if the Inflation Report is to take on primary responsibility for reporting on economic and policy developments, then reporting on these subjects in the Monthly or Quarterly Bulletin and the Annual Report should be cut back or eliminated to free up resources for the Inflation Report and other new publication priorities. This also implies refocusing the Annual Report and the Monthly or Quarterly Bulletin. Typically the Annual Report will become much more focused on reporting on the central bank's performance as a public sector institution, especially its governance, financial, and personnel management. For the Monthly or Quarterly Bulletins, coverage may be limited to statistical reporting, as a document of record (e.g., publishing speeches, news releases, regulatory measures, etc.), or may be reoriented to provide articles on topical monetary policy issues in a form more comprehensible to the general public than the research papers on which the articles may be based.

\section{Release of the Inflation Report and follow-up activities}

Following completion of the Inflation Report, several aspects of its public release need to be managed skillfully to ensure that the central bank gets its messages across clearly to key audiences:

- The time between the finalization of the policy decision and the public release of the Inflation Report should be as short as possible. Any leak can be very damaging to the central bank's reputation, and potentially disruptive to financial markets. ${ }^{50}$ This issue is slightly less critical if the policy decision and underlying assessment are issued as separate documents. Nonetheless, the main Inflation Report should be released as soon as possible after the announcement of the policy decision, as a summary cannot adequately substitute for the full Inflation Report in bolstering the central bank's reputation for careful policy analysis.

- If the Inflation Report is released at the same time that the policy decision is announced, a press release should be prepared for transmission to the wire services stating clearly the central bank's decision on adjusting its policy instruments (including a decision not to adjust them). As discussed earlier, such announcements

\footnotetext{
${ }^{50}$ It is not the provision of information per se that is damaging, but the lack of equal treatment of the media and financial markets that is damaging, as well as the impression that is given of central bank incompetence.
} 
also typically include a very brief review of key economic developments, a discussion of the outlook for inflation, and a sense of the risks surrounding the central scenario.

- It is standard practice for the governor and other senior staff of the central bank to hold a press conference on the release of the Inflation Report. Two particular issues in the management of the press conference may be highlighted:

It is helpful for journalists and market analysts to have at least an hour or two to digest the substance of the Inflation Report (or policy assessment and decision) before the news is released to the general public or markets. An approach that can be recommended over the more familiar "pre-release embargo" is to provide a "lock-up" period with no access to external communications. During this period journalists and market analysts can read the documents and ask for clarification on technical questions, as well as prepare initial reports, prior to the official press conference. A brief period should also be allowed for reports to be filed immediately following the official release of the Report, ${ }^{51}$ so that the press can then focus more carefully on the central bank's presentation and the question and answer session.

o It may be sensible to limit direct participation in the press conference to the press, rather than including market analysts, academics, or others. This would allow the press conference to focus on what will be reported in the media. Market analysts, academics, and selected others could still be allowed to participate in the pre-release lock-up, and could be allowed to observe the press conference.

o It is also common practice for the governor of the central bank to discuss the Inflation Report directly with a relevant parliamentary committee. ${ }^{52}$ Even if such appearances are not required, they offer the central bank a valuable avenue for building broad political support for the policy framework, and increasing understanding within the political establishment of the key issues and trade-offs that the central bank faces.

\section{Special reports}

In addition to regular reports on monetary policy decisions, the central bank may also issue special reports:

- In the event that the inflation target or target range is missed by a significant margin, or is expected to do so, the central bank may be required, by legislation or by agreement, to publish some form of statement. The precise requirements, however, vary significantly from one country to another, and the trend seems to be toward less

\footnotetext{
${ }^{51}$ Since the Report should be released electronically, and posted on the central bank website at the same time, press conference participants should not be disadvantaged relative to those not attending.

${ }^{52}$ A practice recommended under Section 4.1 of the IMF (1999) Code of Good Practices on Transparency. See also Lepper and Sterne (2002) for a cross-country review of parliamentary scrutiny of central banks.
} 
formal, less legalistic approaches to handling such events. ${ }^{53}$ Even in countries where there is no formal obligation for the central bank to report on significant deviations of actual or expected inflation from target, the bank should, at a minimum, discuss the deviation in more detail than normal in its Inflation Report. The basic content of a report on a target miss, whether formal or informal, is similar across countries. The basic elements are a discussion of causes of the deviation of inflation from the target, an explanation of what steps have been taken or are planned to bring inflation back on target, and an indication of the timeframe over which re-convergence to the target is anticipated.

- In a few countries, including New Zealand and Poland, special reports, directed mainly toward the legislature, are prepared on an occasional basis. In the case of Poland, Parliament requires a report, specifically on monetary policy, on an annual basis. In New Zealand, a report on the policy framework and the operation of policy is prepared following national elections, as a briefing for the new government, but is made public. Such reports can be very helpful in informing debate not only about monetary policy issues, but also the interaction of monetary and fiscal policies, labor market policies, and so on, which affect monetary policy, but are outside the control of the central bank.

\section{E. Other Communication Activities}

A wide-ranging public communication program is required beyond the basic elements of accountability and transparency. These communication activities need to be directed at promoting: (i) public support for the basic objectives of monetary policy; (ii) credibility of the central bank's competence and commitment to achieving the objective; (iii) informed public debate over the central bank's conduct of policy; and (iv) financial market understanding of the central bank's approach to assessing new information.

\section{Speeches, interviews, and other public relations}

Speeches provide a prime means of communicating with the general public. In most central banks, senior staff give speeches from time to time. With the adoption of inflation targeting, the need to give speeches is likely to rise considerably as part of the generally increased emphasis on transparency, but also because of the need of the central bank to build a broad public base of support for the policy framework. At the Bank of Canada and the Reserve Bank of New Zealand, speeches are given by the governor, on average, between one and two times per month, with about half on the record and half off the record, and other senior staff are also involved in giving speeches. At the Bank of England, the total number of economics speeches by MPC members (including the governor) averages about two per month, and around six off-the-record talks.

In addition to giving speeches, senior staff should provide interviews, possibly including on television. Increased interaction with the press, and especially if the central bank increases

\footnotetext{
${ }^{53}$ Roger and Stone (2005), Table 3.
} 
communications through television, is likely to require an increase in support for senior staff in dealing with the media, such as through hiring of media specialists, as well as professional training of senior staff in handling interviews, presenting speeches, etc. ${ }^{54}$ In addition, the central bank should plan well ahead a program of speeches on major issues, or target audiences to reach. Usually there are more invitations for senior staff to speak or give interviews than can be accepted, and so the central bank can largely choose the frequency of speeches and interviews, as well as the topics and types of audiences.

At the same time, the central bank should establish rules or guidelines on who should speak when on policy issues. Of particular concern in this context are: (i) rules for establishing "radio silence" ahead of policy meetings; and (ii) who should be able to speak for the bank on policy matters:

- If the central bank has published a schedule for policy meetings, market participants will naturally be looking for clues as to the next policy decision in the period immediately ahead of policy meetings, In such circumstances, it is common practice for the central bank to establish a period of "radio silence" in the period immediately ahead of policy decision-making meetings, to avoid sending misleading signals to markets.

- The central bank should also establish clear internal guidelines regarding the extent to which it is prepared to speak with one voice or with several. If the central bank's decision making is essentially collegial, then it will probably be appropriate to try to present the consensus view on issues. As with the presentation of central bank minutes, this would not preclude laying out areas where debate or differences may exist. Alternatively, if the decision making is much more individualistic, it may be appropriate to allow for a wider diversity of views on issues to be expressed. Nonetheless, and especially if the audience is relatively uneducated on monetary policy issues, too much diversity of opinion may lower the "signal-to-noise" ratio of the central bank's external communications, undermining its effectiveness.

\section{Briefings, workshops, and conferences}

Briefings, workshops, and conferences enhance central bank transparency at a more technical level than possible in speeches. This makes such opportunities very useful in communicating with central bank "watchers" or others with fairly specific interests in the central bank. Conferences and workshops, with participation from abroad as well as from the academic community and other central bank "watchers," can be used both to present the central bank's own research for external scrutiny, and to promote outside interest and research on topics of interest to the central bank. In addition to strengthening the quality of external scrutiny and

\footnotetext{
${ }^{54}$ Central banks in industrial countries tend to be wary of television as a medium, partly because of a perception that television is more likely to distort or sensationalize the message. At the very least, the message is more difficult to control, which underscores the need for professional training if dealing with television.
} 
understanding of monetary policy issues, such meetings help promote high standards of research and analysis within the central bank.

More selective briefings and roundtables can also be used to discuss issues with particular groups, such as parliamentarians, labor leaders, sectoral business groupings, and so on. Such meetings can allow for a sharing of views and concerns that is not otherwise possible. For example, in small open economies, movements in the exchange rate, or in relative prices of some commodities, may lead to significant pressure on some sectors of the economy. Meetings with exporters allows the central bank to acknowledge that it is aware that policy restraint does not necessarily squeeze all sectors equally or fairly, and also allows it to explain more clearly the constraints it may face in dealing with sectoral economic stresses. Such meetings may not solve a problem, but they can help dispel the image of the central bank as an "ivory tower."

\section{Publications}

The development of an Inflation Report can be used as an opportunity to review the central bank's entire suite of publications. As noted earlier, the Annual Report and regular Monthly or Quarterly Bulletins should be refocused to avoid significant overlap with the economic analysis in the Inflation Report. A step that should be considered is to bring in external publishing consultants to advise the central bank on developing a fresh, consistent design to be applied to the range of publications so that the publications are seen to be elements of a complementary set. At the same time, the central bank should review the software and arrangements for publication of documents. In the case of the Inflation Report, deadlines for preparing press releases as well as the main document may be very tight. In such circumstances, the production and printing and distribution processes need to work extremely efficiently and reliably. Technological advances allow for substantial time savings and increased reliability, but it is important to ensure that what is done in-house at the central bank is compatible with the processes or software used by the external printer.

Inflation targeting central banks should increase the public availability of their research. As discussed earlier, workshops provide one opportunity for making central bank research available to the public. However, the central bank should also establish a program for publishing virtually all of the main products of its research efforts. As with the presentation of research at workshops, publication of central bank working papers provides a healthy scrutiny and self-discipline for central bank research. In addition, it can help inform central bank "watchers" as well as encourage others to contribute to research in these areas. More broadly, transparency in the central bank's research will help bolster confidence in the central bank's capability and commitment. A particular recommendation in this regard is for central banks just beginning inflation targeting to publish material on their understanding of the transmission mechanism, their approach to forecasting, and the broad lines of the policy decision-making process.

Many inflation targeting central banks also produce specifically educational materials. In particular, a series of brochures on different aspects of monetary policy and inflation targeting can be produced for distribution to visiting school groups, to persons writing to the central bank, or to other members of the general public. Going a step beyond this, some 
central banks have created monetary policy computer games to give players some sense of the challenges in running monetary policy, or have collaborated with authors writing textbooks dealing with monetary policy issues. Some central banks, including the Bank of England, the Reserve Bank of New Zealand, and the U.S. Federal Reserve have also sponsored competitions between secondary or high schools in monetary policy exercises.

\section{The central bank website}

The central bank website needs to be designed to cater to a wide range of users. The website is becoming an increasingly important means of enabling all types of audiences to inform themselves of those aspects of inflation targeting in which they are particularly interested. Consideration should be given to employing professional external assistance with website design. Objectives should be to:

- Facilitate easy navigation of the website, including in one or more major international languages;

- Make materials available at a range of different levels of detail and catering to the interests of a range of different audiences;

- Cover all the main elements of information needed to understand the framework, formulation, and implementation of inflation targeting;

- Provide easy linkages across relevant areas of the website (or other websites), and to more detailed supporting documentation or research.

A survey of websites of inflation targeting central banks suggests that the following kinds of features might be considered as elements of "best practice” (Table 6):

- Include among the basic subdirectories on the site a subdirectory entitled "Monetary Policy” or "Inflation Targeting”;

- The Monetary Policy or Inflation Targeting subdirectory should provide sections covering topics identified in the transparency recommendations in the IMF (1999) Code of Good Practices on Transparency. These include sections on:

o The central bank's inflation targeting mandate and accountability arrangements, including a nontechnical description, together with appropriate links to relevant legislation or other relevant documents, including the Inflation Report and other policy reviews (such as external reviews);

o A concise, but also precise description of the inflation target, escape clauses, and means of providing accountability, together with links to relevant documents, including periodic reviews or adjustments to the targets, as well as relevant research by the central bank and data on various official and analytical measures of inflation; 
o A description of the main elements of the monetary transmission mechanism, as understood by the central bank, including a clear nontechnical description together with links to relevant empirical research including a description of the central bank's macroeconomic modeling, and key data or data sources;

o A summary of the instruments and operating procedures for implementation of monetary policy, both in domestic money markets and in the foreign exchange market, with links to appropriate documentation and research, including relevant data on key interest rates and exchange rates;

o A clear description of the central bank's monetary policy decision-making structure, including the composition of the committee or committees, qualification criteria and restrictions on appointments and dismissal, terms of appointments, relevant competencies of different decision-making bodies, modes of decision making, publication of information on decisions, and links to relevant documents including all policy statements;

o A schedule of future policy releases, together with links to previous releases, minutes and monetary policy reports.

- For all major documents, such as the Inflation Report, especially those more than 1-2 pages long, it is helpful to provide a very short summary on the website that can be read or printed without downloading the entire document. ${ }^{55}$ The full document should also be readily available for downloading, either in its entirety or by section.

- All subsections and lower-level website pages should aim to facilitate easy navigation across the site through hot linkages, minimizing the need to navigate up and down the hierarchical menu.

\footnotetext{
${ }^{55}$ For example, in several countries, the schedule of releases of policy decisions is only found in one of the monetary policy statements made each year. This information should be made directly accessible on the first page of the central bank website. Similarly, a concise description of the policy mandate and inflation target specification should be available directly from the page on monetary policy, rather than having to read through either the inflation report or the central bank act, or both.
} 
Table 6. Central Bank Website Coverage

\begin{tabular}{llllllll}
\hline \multicolumn{1}{c}{ Country } & IT & Target & Transmission & $\begin{array}{c}\text { Policy } \\
\text { Instruments }\end{array}$ & $\begin{array}{c}\text { Decision } \\
\text { Making }\end{array}$ & $\begin{array}{c}\text { Policy } \\
\text { Calendar }\end{array}$ & $\begin{array}{c}\text { Links to } \\
\text { Materials }\end{array}$ \\
\hline Australia & Yes & Yes & Yes & Yes & Yes & Yes & Yes \\
Brazil & Yes & Yes & No & Yes & Yes & Yes & Yes \\
Canada & Yes & Yes & Yes & Yes & Yes & Yes & Yes \\
Chile & Yes & Yes & Yes & Yes & Yes & Yes & Yes \\
Colombia & No & No & No & No & Yes & No & No \\
Czech Republic & Yes & Yes & Yes & Yes & No & Yes & Yes \\
Hungary & Yes & Yes & Yes & Yes & Yes & Yes & Yes \\
Iceland & Yes & Yes & Yes & Yes & Yes & Yes & Yes \\
Indonesia & Yes & Yes & Yes & Yes & Yes & Yes & Yes \\
Israel & No & No & No & No & Yes & No & Yes \\
Korea & Yes & Yes & Yes & Yes & Yes & Yes & No \\
Mexico & Yes & Yes & Yes & Yes & Yes & Yes & Yes \\
New Zealand & Yes & Yes & Yes & Yes & No & Yes & Yes \\
Norway & Yes & Yes & Yes & Yes & Yes & Yes & Yes \\
Peru & Yes & Yes & No & Yes & Yes & Yes & Yes \\
Philippines & Yes & Yes & No & Yes & Yes & Yes & Yes \\
Poland & Yes & Yes & No & Yes & Yes & Yes & Yes \\
Romania & Yes & No & No & No & Yes & Yes & Yes \\
Slovak & Yes & Yes & No & No & Yes & Yes & Yes \\
South Africa & Yes & Yes & Yes & Yes & Yes & Yes & Yes \\
Sweden & Yes & Yes & Yes & Yes & Yes & Yes & Yes \\
Thailand & Yes & Yes & Yes & Yes & Yes & Yes & Yes \\
Turkey & Yes & Yes & Yes & Yes & Yes & Yes & Yes \\
United Kingdom & Yes & Yes & Yes & Yes & Yes & Yes & Yes \\
\hline Notes and & Centrats & & & & \\
\hline
\end{tabular}

Notes and Sources: Central bank websites. 


\section{Appendix. The Inflation Report}

Most central banks already provide some form of report on economic developments in their Annual Report, or Monthly or Quarterly Bulletins, which can provide a very useful basis on which to develop an Inflation Report. This appendix, therefore, focuses in particular on those elements of an Inflation Report that are most likely to involve unfamiliar territory. These include: (i) the focus on inflation outcomes and inflation drivers in the retrospective analysis of economic and financial developments; (ii) the discussion of the outlook for inflation; and (iii) discussion of the policy assessment and policy decision.

The Report should be aimed at a broad audience of interested, but non-expert readers. Use of technical jargon should be minimized. The main messages or overall assessments should be stated clearly up front, and then evidence presented to support these messages. Technical issues or more in-depth analysis of particular issues and developments can be dealt with in "boxes" in the text, so that the flow of the main text is not interrupted.

Inflation Reports typically contain three basic elements: a review of recent economic and inflation developments; a discussion of the outlook for economic activity and inflation; and a policy decision based on a discussion of risks surrounding the central forecasts. Although these elements are sometimes be split up between different documents, one way or another, almost all inflation targeting central banks publish all three elements, and all should do so to provide meaningful policy accountability. ${ }^{56}$

The backward-looking section of the Inflation Report plays two essential functions: (i) providing an accounting for recent inflation outcomes and their determinants; and (ii) setting the stage for the discussion of the outlook for economic activity and inflation. The coverage of the review of recent economic developments typically includes the following elements:

- Recent headline and core inflation outcomes. This is often made into a distinct subsection, and placed at the front of the recent economic developments chapter to underscore its accountability function. A graph showing recent inflation and the target range and center should be standard. The analysis should focus on accounting for the recent evolution of inflation relative to the target and relative to expectations. Reporting on a range of measures of core inflation can be useful in distinguishing between the generalized trend of inflation and the impact of specific relative price developments. In addition, especially in relatively open economies, it is useful to discuss movements in the prices of tradable and non-tradable goods and services, if such series are available. If the target range has been missed, or is likely to be missed, or a major relative price shock has occurred, more detailed discussion would be warranted, even if a separate report is required under the central bank's accountability framework;

\footnotetext{
${ }^{56}$ As noted in the main text, some central banks separate the policy assessment and decision from the rest of the Inflation Report. In a few cases, the discussion of recent economic developments may also be in a separate document from the more forward-looking analysis (e.g., Bank of Israel).
} 
- Aggregate Demand developments. This discussion should focus on the evolution of the main expenditure components of real GDP and relevant indicators (e.g., retail sales, consumer and business confidence surveys, etc.), emphasizing the implications for excess demand and pressures on inflation.

- Aggregate Supply developments. This discussion typically reports on three subcomponents: (i) production GDP data and sectoral economic indicators; (ii) labor market developments, including supply and demand indicators and wage developments; and (iii) international and domestic commodity price developments.

- Balance of payments developments. Discussion of the balance of payments as a distinct section typically often sits uneasily with the other discussions focused more directly on inflation pressures. In general, it might be more appropriate to discuss current account developments as indicators in the discussion of aggregate demand or, in some cases, aggregate supply, while capital account developments are discussed in the context of financial market developments. In any event, the discussion of balance of payments developments needs to be careful to avoid giving the impression that it represents a policy objective in competition with the inflation objective.

- Financial and monetary developments. Discussion of these areas varies considerably across countries, and is often only weakly linked to the analysis of inflation pressures. An appropriate coverage could include: (i) recent fiscal developments affecting interest rates and the exchange rate; (ii) external financial and capital account developments affecting interest rates and the exchange rate; (iii) recent monetary and credit developments, linking to the earlier discussion of demand and sectoral developments; and (iv) a review of monetary policy adjustments since the last Inflation Report.

The Inflation Report should contain a section discussing the outlook for activity and inflation:

- The economic outlook. Whether the central bank uses a fairly complete macroeconomic model in forecasting or not, the discussion of the economic outlook should explain how recent developments are expected to be transmitted through the economy to future inflation outcomes. The central bank's broad view of the policy transmission mechanism should be clear. An effective way to organize this discussion is to have it go through the various elements that would be found in a standard openeconomy inflation equation: expectations and inertial components, excess demand pressures (reflecting the expected evolution of expenditure components and supply), and exchange rate effects. The discussion of each of these elements would, in turn, involve discussion of assumptions and evidence supporting the forecast. The presentation should be non-technical, and make extensive use of graphics. Boxes should be used to cover specific topics in greater detail.

- Presentation of forecasts. Mishkin (2004a) Table 1 indicates that, although almost all inflation targeters present their inflation forecasts, fewer present forecasts for output growth or output gaps, and very few show forecasts for the policy interest rate. An 
issue that is currently being debated among central bankers and theoreticians is how far central banks should go in presenting their forecasts. ${ }^{57}$ Mishkin lays out clearly the basic lines of argument on each side. The chief argument in favor of presenting the forecasts is that since policy decisions are largely based on the forecasts (and surrounding risks), presenting the forecasts in some detail will increase policy transparency, central bank discipline and credibility. ${ }^{58}$ On the other side, it is argued that: (a) it would be misleading for the central bank to present a forecast path for interest rates since the policy decision is only a commitment to the first step; ${ }^{59}$ and (b) the public may have difficulty in understanding the conditional nature of the forecasts. The bottom line, as Mishkin observes, is that transparency of the projections should not be increased beyond the point where it hinders rather than helps presentation of a clear policy "story."

Most countries could probably go much further in terms of presenting their forecasts than they do before it would hinder presentation of the overall story. In particular, projections for some of the key variables and assumptions in the forecasts-GDP growth, the output gap, exogenous variables such as foreign output, inflation and commodity prices, and fiscal policy variables — could probably all be published and be helpful in explaining the economic outlook and areas of uncertainty. The parts of the forecasts where the greatest reservations about publishing would be the forecast paths for interest rates and the exchange rate. The experiences of countries like New Zealand and Norway indicate that publication of these parts of the forecasts are not a recipe for disaster. However, it is important to treat seriously concerns about public confusion over conditional versus unconditional forecasts. Before publishing forecasts in full detail, therefore, it would be advisable for the central bank to conduct a careful program of education of the press and key bank watchers to ensure that they are clear on the conditional nature of the forecasts and can convey that to the wider public.

- Risk analysis and policy assessment. In addition to providing a central forecast scenario, it is important for the report to discuss uncertainties and risks surrounding the main forecast, since these need to be taken into account in reaching policy decisions. Key areas of uncertainty include the current state of the economy and inflation pressures, the structure of the economy and the monetary policy transmission mechanism, and future economic developments. The different kinds of uncertainty have different implications for policy. ${ }^{60}$

\footnotetext{
${ }^{57}$ See for example, Edey and Stone (2004), Mishkin (2004b), and other papers presented at the Reserve Bank of Australia conference on “The Future of Inflation Targeting," August 9-10, 2004, and Archer (2005) and other papers presented at the Swedish Riksbank workshop on "Inflation targeting: implementation, communication and effectiveness,” June 10-12, 2005. See also Rudebusch and Williams (2006).

${ }^{58}$ See also Archer (2005).

${ }^{59}$ This line of argument is also made in King (2006).

${ }^{60}$ See, e.g., Conway (2000) for an overview of uncertainty and monetary policy implications.
} 
A number of techniques are used to illustrate uncertainties involved in the outlook. The "fan chart" developed by the Bank of England is used to convey the degree of uncertainty surrounding the inflation forecast that results from uncertainty about the state and structure of the economy, both of which result in forecast errors. Alternative scenarios can also used to illustrate the implications of uncertainty about the state and structure of the economy (e.g., using scenarios with different estimates of an output gap, or a different exchange rate pass-through coefficient). More commonly, however, alternative scenarios are used to consider uncertainty about future developments (e.g., different world oil price scenarios), or alternative policy scenarios. Alternative scenarios can also be used to illustrate the implications of faster or slower policy reactions to developments.

In the policy assessment, the main focus can then be on how the risks and uncertainties have been weighed up in reaching a decision on the appropriate policy stance. This involves not only a judgment on the relative importance of different kinds of risks, but also whether policy should take a "wait-and-see” position or act now. In both areas, views of individual policy makers may well differ. Conveying the flavor of the policy discussion involved in coming to an agreed course of action provides readers with valuable insights into the central bank's approach to policy implementation, and can also provide some sense of the probable future direction of policy adjustments.

In addition to the main components, Inflation Reports include a variety of other secondary supporting elements. This is very helpful in allowing the Report to cater to different audiences. For example, the main text of the Report needs to be intelligible to a fairly broad, non-expert audience, but additional detail can be provided for particular audiences such as market analysts, academics, or investors. Common items include:

- A brief (one page) description of the main elements of the framework, including (a) the central bank's inflation targeting mandate; (b) the specification of the target; (c) the central bank's policy decision-making structure; (d) the policy instrument; ${ }^{61}$

- A calendar of future releases of policy decisions and reports;

- A chronology of recent policy announcements and press releases;

- Graphs and tables should be used extensively to complement text and to reduce the need to clutter the text with numbers. The graphs themselves should be uncluttered, and tables kept simple;

- "Boxes" of 1-2 pages in the main text to discuss in greater detail than appropriate in the main text: (a) standard technical issues in inflation targeting, such as concepts and measurement of core inflation, potential output, exchange rate pass-through, or inflation expectations formation or measurement; (b) monetary policy implications of specific conjunctural developments such as significant changes in equity or property prices, terms of trade or other international developments, demographic/immigration

${ }^{61}$ See, e.g., the Inflation Reports of the Norwegian and Canadian central banks. 
changes; and (c) analytical issues such as the policy implications of different types of uncertainty, or the implications of exchange rate or interest rate smoothing;

- A glossary of terms used in the main text.

Most central banks already produce publications including some elements that can be very helpful in developing an Inflation Report. Almost all central banks produce monthly or quarterly statistical reports, and many of these include sections reporting on recent macroeconomic, financial, or balance of payments developments. Annual Reports also often contain such analysis. The staff, software, and technical skills involved in preparing the text, tables, charts, layout, printing, distribution, and other requirements of a professional publication can be readily adapted to the needs of an Inflation Report. 


\section{REFERENCES}

Archer, D., 2005, “Central bank communication and the publication of interest rate projections," Presented at the Sveriges Riksbank workshop on "Inflation targeting: implementation, communication and effectiveness,” June 10-12, 2005, Stockholm.

Arnone, M., B. Laurens, and J.-F. Segalotto, 2006, “The Measurement of Central Bank Autonomy: Survey of Models, Indicators, and Empirical Evidence,” IMF Working Paper WP/06/227 (Washington: International Monetary Fund).

Barro, R., and R. Gordon, 1983, "Rules, discretion and reputation in a model of monetary policy,” Journal of Monetary Economics Vol. 91, pp. 103-15.

Batini, N., P. Breuer, K. Kochhar, and S. Roger, 2006, “Inflation Targeting and the IMF," IMF Board Paper SM/06/33 (Washington: International Monetary Fund).

Briault, C., A. Haldane, and M. King, 1996, “Central Bank Independence and Accountability: Theory and Evidence,” Bank of England Quarterly Bulletin (February), pp. 63-68.

— Effective Monetary Policy (London: MacMillan), pp. 299-326.

Blinder, A., C. Goodhart, P. Hildebrand, D. Lipton, and C. Wyplosz, 2001, “How Do Central Banks Talk?” Geneva Reports on the World Economy 3 (ICMB/CEPR).

Blinder, A., and C. Wyplosz, 2004, “Central Bank Talk: Committee Structure and Communication Policy,” mimeo.

Brook, A-M., O. Karegedikli, and D. Scrimgeour, 2002, “Assessing alternative inflation targets: growth effects and other costs and benefits," in Policy Targets Agreement: Reserve Bank briefing note and related papers, September 2002, Reserve Bank of New Zealand, pp. 22-50.

Canales-Kriljenko, J., T. Kisinbay, R. Maino, and E. Parrado, 2006, “Setting the Operational Framework for Producing Inflation Forecasts,” IMF Working Paper 06/122 (Washington: International Monetary Fund).

Carpenter, S., 2004, “Transparency and monetary policy: what does the academic literature tell policy makers?” BGFRS Finance and Economics Discussion Series 2004, p. 35.

Citu, F., 2002, "Review of the literature on the comparison of price level targeting and inflation targeting,” The Policy Targets Agreement: Reserve Bank Briefing Note and Related Papers, Reserve Bank of New Zealand Bulletin, September, pp. 67-71.

Conway, P., 2000, "Monetary policy in an uncertain world,” Reserve Bank of New Zealand Bulletin, 63 Vol. (3), pp. 5-15. 
Cottarelli, C., 1994, "Should an 'Independent' Central Bank Control Foreign Exchange Policy?” Chapter 12 in T. Baliño and C. Cottarelli, eds., Frameworks for Monetary Stability, (Washington: International Monetary Fund).

— 1995, "Limiting Central Bank Credit to the Government: Theory and Practice," MAE Operational Paper OP/95/5 (Washington: International Monetary Fund).

De Haan, J., F. Amtenbrink, and S. Eijffinger, 1998, “Accountability of Central Banks: Aspects and Quantification," Tilburg University Center for Economic Research Discussion Paper 54.

—_, and S. Waller, 2004, "The Transparency and Credibility of the European Central Bank,” Journal of Common Market Studies, V. 42 (4), pp. 775-94.

Debelle, G., and S. Fischer, 1994, “How Independent Should a Central Bank Be?” in J. Fuhrer, ed., 1994, Goals, Guidelines, and Constraints Facing Monetary Policymakers, (Boston: Federal Reserve Bank of Boston), pp. 195-221.

Edey, M., and A. Stone, 2004, “A perspective on Monetary Policy Transparency and Communication," Presented at the Reserve Bank of Australia conference on "The Future of Inflation Targeting," (Reserve Bank of Australia, Sydney), pp. 73-100.

Edwards, J., 2004, “Discussion [of Edey and Stone],” Presented at the Reserve Bank of Australia conference on "The Future of Inflation Targeting," (Reserve Bank of Australia, Sydney), pp. 100-07.

Eijffinger, S., and P. Geraats, 2002, “How transparent are central banks?” CEPR Discussion Paper 3188.

Fischer, S., 1994, "Modern Central Banking," in Capie, F., S. Fischer, C. Goodhart, and N. Schnadt, eds., 1994, The Future of Central Banking, (Cambridge: Cambridge University Press), pp. 262-308.

Fischer, S., 1995, “Central Bank Independence Revisited,” American Economic Review 85 Vol. (2), pp. 201-06.

_ , 2006, “The Role of the Central Bank: The Israeli Case,” Israel Economic Review 4 Vol. (1), pp. 15-25.

Fracasso, A., H. Genberg, and C. Wyplosz, 2003, "How do Central Banks Write? An Evaluation of Inflation Targeting Central Banks," Geneva Reports on the World Economy Special Report 2 (ICMB / Norges Bank/CEPR). 
Fry, M., and others, 2000, "Key Issues in the Choice of Monetary Policy Framework,” Part 1 of L. Mahadeva and G. Sterne, eds., Monetary Frameworks in a Global Context, (London, Bank of England).

Hahn, V., 2002, “Transparency in Monetary Policy: A Survey,” IFO Studien Zeitschrift fur Empirische Wirtschaftforschung Vol. 48 (3), pp. 429-55.

International Monetary Fund, 1998, “Elements of Central Bank Autonomy and Accountability,” MAE Operational Paper OP/98/1 (Washington: International Monetary Fund).

— 1999, Code of Good Practices on Transparency in Monetary and Financial Policies: Declaration of Principles (Washington: International Monetary Fund).

— 2005, "Selected Country Experience in Implementing the Code of Good Practices on Transparency in Monetary and Financial Policies,” SM/05/334 (Washington: International Monetary Fund).

Ize, A., 2005, “Capitalizing Central Banks: A Net Worth Approach,” IMF Working Paper 05/15 (Washington: International Monetary Fund).

Jackman, P., 2002, “The Reserve Bank’s external communications,” Reserve Bank of New Zealand Bulletin, Vol. 65 (1), pp. 28-33.

King, M., 2006, Speech, Mansion House, London, June 21.

Kydland, F., and E. Prescott, 1977, "Rules Rather than Discretion: The Inconsistency of Optimal Plans,” Journal of Political Economy Vol. 85, pp. 473-92.

Laxton, D., and A. Scott, 2000, “On Developing a Structured Forecasting and Policy Analysis System Designed to Support Inflation-Forecast Targeting (IFT),” in Inflation Targeting Experiences: England, Finland, Poland, Mexico, Brazil, Chile, ed. by Central Bank of the Republic of Turkey (Ankara: Central Bank of the Republic of Turkey), pp. 6-63.

Lepper, J., and G. Sterne, 2002, "Parliamentary Scrutiny of Central Banks in the United Kingdom and Overseas,” Bank of England Quarterly Bulletin, Autumn 2002, pp. 274-84.

Lucas, R., 1972, “Expectations and the Neutrality of Money,” Journal of Economic Theory Vol. 4, pp. 103-24.

__ 1976, “Econometric Policy Evaluation: A Critique,” Carnegie-Rochester Conference Series on Public Policy Vol. 1, pp. 19-46. 
Lybek, T., and J. Morris, 2004, “Central Bank Governance: A Survey of Boards and Management,” IMF Working Paper 04/226 (Washington: International Monetary Fund).

Mishkin, F.S., 2000, “What Should Central Banks Do?” Federal Reserve Bank of St. Louis Review, Vol. 82(6), pp.1-13.

_ 2004a, “Can Inflation Targeting Work in Emerging Market Countries?” NBER Working Paper 10646.

—, 2004b, “Can Central Bank Transparency Go Too Far?” NBER Working Paper 10829.

Roger, S., and M. Stone, 2005, “On Target? The International Experience with Achieving Inflation Targets” IMF Working Paper 05/163 (Washington: International Monetary Fund).

Rudebusch, G., and J. Williams, 2006, "Revealing the Secrets of the Temple: The Value of Publishing Central Bank Interest Rate Projections,” NBER Working Paper 12638.

Stella, P., 2005, “Central Bank Financial Strength, Transparency, and Policy Credibility,” IMF Staff Papers 52 (2), pp. 335-64 (Washington: International Monetary Fund).

Svensson, L., 2001, Independent Review of the Operation of Monetary Policy in New Zealand: Report to the Minister of Finance (Stockholm: Institute for International Economic Studies, University of Stockholm).

Sullivan, K., 2003, “Profits, Dividends and Capital—Considerations for Central Banks,” in Accounting Standards for Central Banks (London: Central Banking Publications).

— 2005, “Transparency in Central Bank Financial Statement Disclosures,” IMF Working Paper 05/80 (Washington: International Monetary Fund).

Tuladhar, A., 2005, “Governance Structures and Decision-Making Roles in Inflation Targeting Central Banks,” IMF Working Paper 05/183 (Washington: International Monetary Fund).

Vandenbussche, J., 2006, “Elements of Optimal Monetary Policy Committee Design,” IMF Working Paper, forthcoming (Washington: International Monetary Fund).

Woodford, M., 2005, “Central Bank Communication and Policy Effectiveness,” NBER Working Paper 11898. 